\title{
Numerical Investigation of Non-Linear Equivalent-Frame Models for Regular Masonry Walls
}

\author{
Rossella Siano $^{1^{* \dagger}}$, Pere Roca ${ }^{2}$, Guido Camata ${ }^{1}$, Luca Pelà2 ${ }^{2}$ Vincenzo Sepe ${ }^{1}$, Enrico Spacone ${ }^{1}$, \\ Massimo Petracca ${ }^{1}$ \\ ${ }^{1}$ Department of Engineering and Geology, University “G. D’Annunzio” of Chieti Pescara, \\ viale Pindaro 42, I-65127 Pescara, Italy \\ ${ }^{2}$ Department of Civil and Environmental Engineering, Universitat Politècnica de Catalunya (UPC-BarcelonaTech) \\ Jordi Girona 1-3, Barcelona, Spain
}

\begin{abstract}
The accuracy of the Equivalent Frame Method (EFM) in modelling the seismic non-linear behaviour of unreinforced masonry (URM) buildings is investigated for regular walls (i.e. walls with regular openings' distribution) with different pier-to-spandrel geometrical relations. The developed EFM is composed of pier and spandrel elements with spread plasticity to simulate the flexural behaviour and lumped plasticity to simulate the shear behaviour. The investigation focuses on checking, by means of comparison with Finite Element Model (FEM) assumed as reference, the applicability of EFM to existing buildings. These structures are often characterised by geometrical schemes difficult to be represented by ideal frames. To point out the role of the geometrical configuration, the numerical results provided by the two modelling approaches are compared for different representative cases of regular walls characterized by pier-spandrel configurations rather typical in existing URM buildings. In addition to the innovative EFM approach, based on a fiber discretized beam element, also a more traditional approach, based on beam elements with lumped plasticity, is included in the comparative study. The two different EFM approaches were implemented in the software Midas GEN ( ) [44], while an open source software was used to implement the FEM (Kratos Multiphysics [59-60]). All the models were used to perform static non-linear analyses under equivalent loading and boundary conditions.

The evaluation of EFM and FEM is derived from a comparative simulation of a two-storey URM wall experimentally tested by other researchers. Two alternative approaches are assumed for the definition of piers' effective heights in the EFM, i.e. the models proposed by Dolce [1] and Augenti [2]. The results demonstrate that remarkable differences may be detected in EFM and FEM predictions of the shear capacity and damage mechanisms as a function of pier-spandrel geometrical configurations. This result highlights the need for a cautious application of EFM to existing URM structures.
\end{abstract}

KEY WORDS: Masonry structures; URM walls; Equivalent-Frame Models; seismic vulnerability; non-linear static analysis.

\section{INTRODUCTION}

The study of the structural behaviour of new buildings is usually based on the quantitative evaluation of stress and deformation fields by means of numerical models. This approach is not easily applicable to the heterogeneous portfolio of existing masonry buildings. The mechanical inhomogeneity of the material and the huge variety of materials and constructive techniques, in fact, make the study of unreinforced masonry (URM) structures very challenging. The problem is further complicated by the complexity of the possible walls' geometrical configurations. In most cases, existing masonry buildings were non-engineered at the time of their construction and may have undergone many changes over time.

${ }^{*}$ Correspondence to: Rossella Siano, Department of Engineering and Geology, University of Chieti-Pescara, viale Pindaro 42, I-65129 Pescara - Italy.

†E-mail: rossella.siano@unich.it 
The classical approach to the structural modelling of masonry constructions focused on simplified models aimed at evaluating the safety conditions of singular structural elements, e.g. columns, arches, vaults, etc. [3]. Only at the end of the seventies, the attention moved to global models by extending to masonry structures the methods initially developed in different fields of structural engineering, such as the Discrete Element Method (DEM) [4, 5] or the Finite Element Method (FEM) [6-8]. The difficulty in characterizing the mechanical parameters of the material and the high computational cost of detailed models prevented their application to ordinary buildings and therefore their wide diffusion. For this kind of structures, the research focused mainly the formulation of simplified modelling approaches derived from the study of more engineered structures, like reinforced concrete (RC) and steel structures. The Equivalent Frame Method (EFM) [9-10] is one of the most known approaches derived from the analogy of the actual structure with a simple structural scheme, like a frame.

The widespread use of the EFM for non-linear analysis of URM structures stems from the large reduction of computational cost that it allows. As known, the EFM is based on the assumption that a masonry load-bearing wall can be modelled as a plane frame. The shear wall in-plane behaviour is then studied by discretizing it into discrete components (piers and spandrels) connected through rigid links (node panels), as shown in Figure 1.
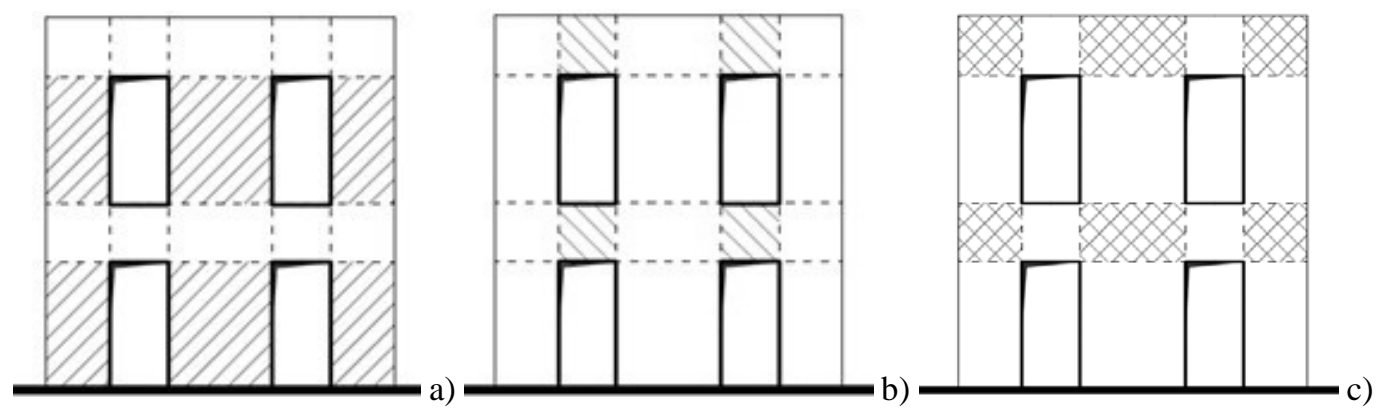

Figure 1: Discretization of a masonry wall into macro-elements: piers (a), spandrels (b) and node panels (c).

In this approach, a crucial role is played by the definition of the macro-elements geometry, particularly in the case of piers which represent the main resisting elements of the equivalent frame scheme. Two approaches are commonly used for the definition of the piers effective height. The first criterion, proposed by Dolce [1], allows the identification of the effective deformable length of piers by applying a simple geometrical rule accounting for both the equivalent stiffness of the pier and the deformability of the surrounding spandrels. By updating the criterion provided by FEMA 356 [11], Augenti [2] proposed an alternative criterion in which the effective height of piers is defined as the height of consecutive opening from the side of the earthquake loading. Recent studies [12, 13] have investigated the influence of the mentioned criteria on the reliability of EFM results demonstrating their strong sensitivity to the geometry of the equivalent frame schemes.

Numerical tests and validation studies based on the comparison with experimental tests [14-17] have shown that the EFM can be successfully applied to the structural analysis of new URM buildings. At the same time, some uncertainties still hamper its application to the structural modelling of existing URM buildings. In this case, in fact, the simplified interpretation of the structural behaviour proposed by EFM is more uncertain. In particular, the application of EFM may be limited [18] by the presence of irregular geometries [19]. In case of regular walls, i.e. walls with openings aligned along both vertical and horizontal directions, the use of EFM may be critical in presence of pier-to-spandrel geometrical relations that do not comply with a classical frame configuration. Specifically, the EFM does not provide satisfactory results in the case of walls including squat piers or spandrels. In specific, Siano et al. [18] have demonstrated the limitations of EFM in modelling the response of façades with cross sections' inertia of spandrels 10 times greater than those of the piers.

Further uncertainties can also arise in the identification of structural details, loading history, occurred damage and eventual refurbishment interventions. The correct inclusion of these details in the equivalent frame scheme is still troublesome in case of existing constructions because of the morphological variations that usually affect these structures over their lifecycle [20-22].

An accurate and systematic validation of EFM is therefore necessary to define clear limits for its applicability to URM existing constructions. In line with this purpose, Siano et al. [18, 23, 24] presented a wide parametric investigation to study the limits and potential application of the EFM approach to regular and irregular 2D walls. The investigation involved a wide sample of URM walls characterized by different geometrical configurations and tested in the linear and non-linear ranges. The shear capacity and damage mechanisms predicted by equivalent- 
frame models (EFM) were compared with Finite Element Models (FEM), assumed as reference. The EFM and FEM results were also compared with experimental results available in the scientific literature [25].

Linear analyses both on regular and irregular façade configurations, reported in [18], showed the role of the geometrical configuration of the wall with respect to its ideal EFM representation. It was shown that differences between EFM and FEM results cannot be neglected in case of significantly irregular distribution of openings. The same is found for regular walls with pier-to-spandrel geometrical relations not compatible with a classical frame configuration, although representative of many old buildings. This fact leads to the distinction, measured by appropriate non-dimensional parameters, between frame-like walls - for which EFM can provide acceptable results and non-frame-like walls.

However, given the strong non-linearity of masonry structures, the validation of a numerical approach cannot be limited to the linear field. In this paper, the results obtained in the linear analyses [18] are extended to the non-linear field. Namely, non-linear static analyses are used for the assessment of the seismic response of 2D walls representative of existing URM buildings, as they represent a widespread tool in the engineering practice [26, 27]. The non-linear validation reported here focuses only on regular geometries, selected among those showing a problematic behaviour in the linear analyses described in [18].

\section{NON-LINEAR MODELS FOR MASONRY WALLS}

The main cause of non-linearity in the behaviour of masonry is its small or almost negligible tensile strength. This low tensile strength causes cracking of the resisting cross-sections and the reduction of the effective resisting area to the portions working in compression. The mechanical response becomes non-linear even under low stress levels.

Given the relative ease of application of linear elastic analysis, many studies initially derived failure models from the elastic study of masonry components [28] and applied those linear models to complex monumental constructions [29-30]. However, the linear elastic approach cannot be considered adequate to describe the structural behaviour of masonry constructions, especially when simulating their seismic response. The interest towards the seismic performance of masonry constructions has motivated the development of non-linear structural models during the last decades. In this context, the application to masonry structures of non-linear Finite Elements models [6-8] provided a wide range of solutions characterized by different modelling scales. The level of detail of FEM models ranges, in fact, from a macro-scale approach to more refined micro-models.

In case of macro-models [8, 21, 31-33], masonry is modelled as a homogenous ideal continuum by neglecting the interaction between the single components (e.g. bricks and mortar). These models require a careful mechanical calibration that can be carried out directly by deriving homogenized continuum parameters by experimental tests on large-scale specimens. The properties of the ideal continuum can be derived, as an alternative, by applying numerical homogenization techniques to the mechanical properties of the single masonry components. Even if efficient from a computational point of view, FE macro-models show limitations in the description of local phenomena or strong discontinuities at micro-scale level.

FE micro-models [34-35] overcome these limits by explicitly modelling the response of each component (units, mortar and their mutual interfaces) of masonry with its own geometry and material parameters. The non-linear response of units and mortar joints is usually modelled by using continuum finite elements, while the interfaces between them is simulated by discontinuous elements. In this way, the complex interaction between units and mortar is accurately represented. However, micro-models require very large computational effort, so that these models are suitable and convenient only for modelling small structural elements or walls.

Multiscale modelling is a novel computational approach based on the exchange of information between the macro-scale and the micro-scale analyses [36]. The macro-scale is that of the total structure, represented as a homogenised continuum, whereas the micro-scale is used to investigate the local behaviour of a representative volume element (periodic cell) including the description of all the material components (units and mortar joints). Computational homogenization techniques are used to derive the homogenised properties from the micro-scale to feed the macro-model. This advanced method has recently been applied to both the in-plane and the out-of-plane analyses of masonry walls [37].

In parallel to the complex FEM approaches, simplified approaches have been proposed, based on the simulation of discrete portions of masonry as bi- or mono-dimensional elements with non-linear behaviour. All these proposals are commonly included in the category of EFM approach, since they study masonry walls by identifying them with an equivalent plane frame [9-10]. In the EFM framework, the material non-linearity can be taken into account by means of two different approaches, i.e. lumped plasticity and spread plasticity models. In the former models, the inelasticity is concentrated in limited portions of the structural elements. In this case, mono-dimensional beam 
elements are usually modelled by an elastic central part and nonlinear terminal parts, defined as plastic hinges. An efficient example of lumped plasticity model is the one proposed by Magenes and Della Fontana [39]. In the case of spread plasticity models, the mechanical non-linearity of masonry is included over the whole length of the structural elements. The in-plane behaviour of masonry walls is then studied by discretizing them in a system of bidimensional macro-elements, whose non-linear mechanical models accounts for masonry cracking and crushing. An example of this approach was TREMURI proposed by Lagomarsino et al. [40, 41].

In this paper, the non-linear behaviour of masonry is simulated by using both the approaches with lumped and spread plasticity. An innovative force-based approach [15], derived by the one for r.c. beams [42-43], and a more traditional one are contemporarily tested by comparing their results with a refined FEM, which uses a micromodelling approach. The first EF model results from the contemporarily application of a beam element with spread plasticity to simulate the flexural behaviour and concentrated non-linear hinges to simulate the shear behaviour, while the second EF model is based on a beam element with lumped plasticity. All the numerical models used for the comparative study are described in the following paragraphs.

\subsection{Non-linear Equivalent Frame modelling of URM walls: a force-based approach}

The implementation of the EFM follows the recently proposed extension of a force-based frame element [42-43] to the description of the non-linear in-plane behaviour of masonry [15]. This approach assumes a spread plasticity model and considers a fiber discretization of the cross-sections for each beam element (Figure 2). The fiber discretization of the cross-sections simulates the axial and flexure interaction. Integration of the fiber stresses provides the sections' axial force and bending moments, while integration of the section forces at given locations (the integration points) yields the element end forces.

The model accounts for the shear response too by adding a non-linear spring (Figure 2) to the fiber-section frame element. The spring non-linear response, accounting for the shear deformation only, is defined by means of phenomenological non-linear shear-distortion $(V-\gamma)$ constitutive laws. The two models work as a series system, as shown in Figure 2, so that both the flexural and shear failure mechanisms can be accounted for. Each component of the model can be easily calibrated by means of experimental tests or standards' prescriptions. The models adopted in the present work have been implemented in the software Midas GEN ( [44].
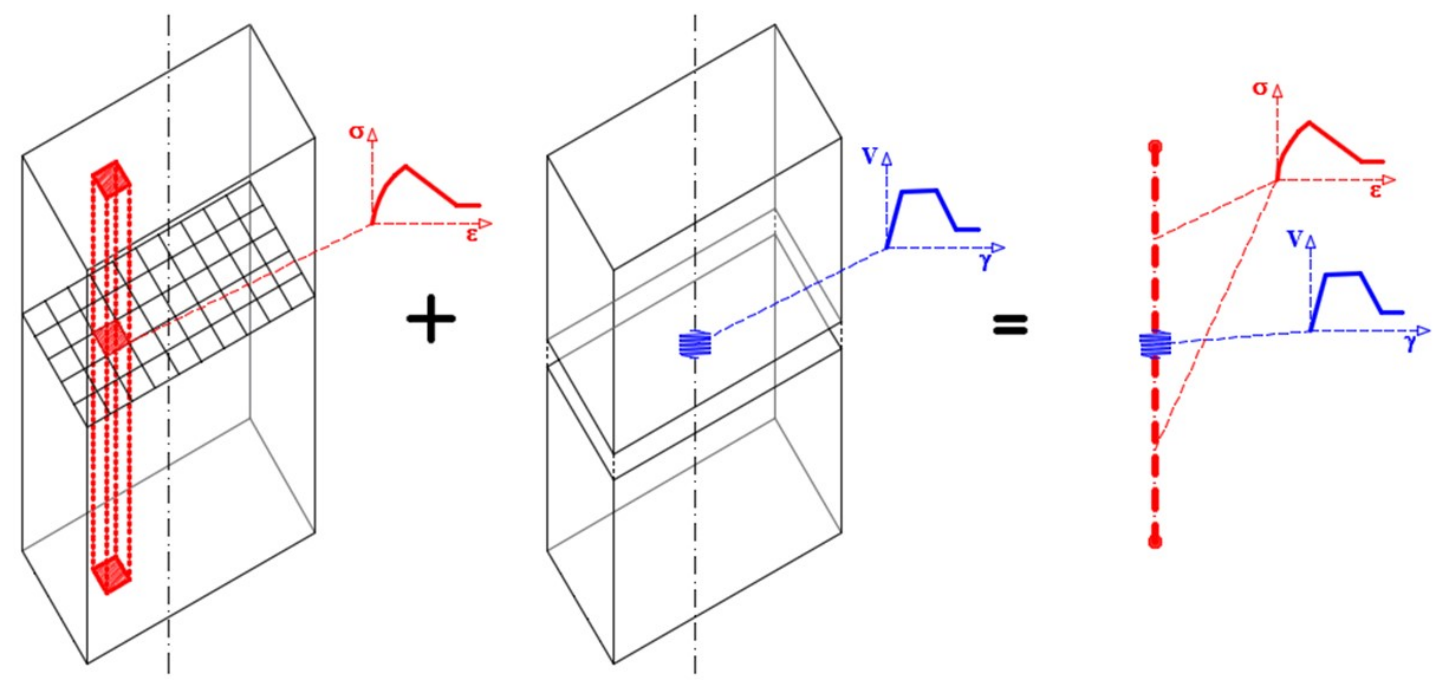

Figure 2: Non-linear model for mono-dimensional elements in EFM.

The non-linear response of the fibers is simulated by the mono-axial constitutive law provided by Kent and Park [45] and then updated by Scott et al. [46] (Figure 3a). This law, initially defined for concrete, is adequate to reproduce the main properties demonstrated by masonry in experimental tests, as shown in [14]. It accounts for the initial linear elastic branch, the hardening before the peak stress and the linear softening branch in the post-peak phase.

The model proposed by Kent and Park [45], presented in graphical form in Figure 3a, completely neglects the tension strength of the structural material. This assumption is suitable to masonry walls, given its negligible tensile 
strength. Raka et al. [15] proposed the same law for the calibration of EF models, while De Santis and de Felice [47] applied it for modelling single masonry structural elements. In this paper, the numerical simulations of an experimental test performed on a full-scale building prototype [25] provide additional confirmation of the accuracy of the proposed mechanical model.

The simulation of the in-plane shear behaviour is achieved through the calibration of the $V-\gamma$ constitutive law associated to the non-linear spring at the centre of each mono-dimensional element. The selected law is a tri-linear degrading law defined according to a Takeda Tetra-linear model (Figure 3b). Focusing on the positive part of a single loading cycle, four branches compose the reference shear law. The coordinates of the edge points of each branch are defined by following mechanical criteria provided both by international standards [11,48-51] and experimental calibration present in the scientific literature [52-53].
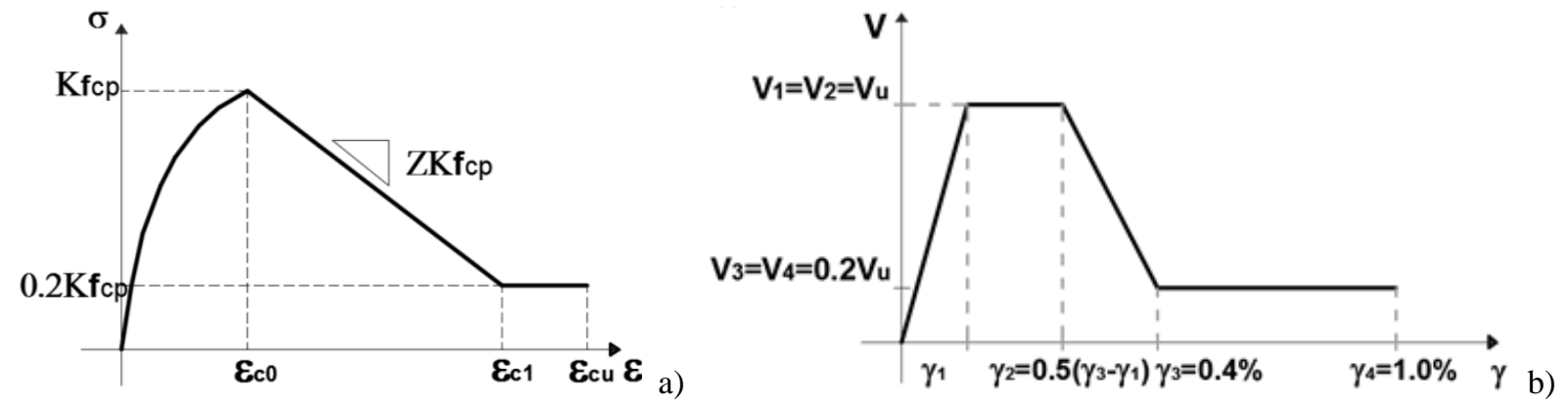

Figure 3: (a) Kent and Park [45] uniaxial constitutive law used for the fiber of masonry and (b) Takeda tetra-linear model used to model the masonry panel shear behaviour.

The first branch is linear elastic up to the peak shear strength $\left(V_{1}\right)$. The maximum shear capacity corresponds to the shear resistance of each panel, as given by the more critical of the two possible shear mechanisms, i.e. diagonal cracking and sliding. The evaluation of the ultimate shear strength corresponding to the sliding shear mechanism follows the criterion provided by the Eurocode 6 [48], while the shear resistance associated to diagonal cracking is evaluated by applying the formula currently considered by the Italian standards [50] as proposed by Turnšek and Čačovič [52] and updated by Tomaževič [53].

The deformation at peak shear strength is given by the ratio between the ultimate shear capacity of the masonry panel and the initial elastic shear stiffness $\left(\gamma_{I}=V_{1} / K_{s}=V_{1} / G A_{s}\right.$, where $V_{1}$ is the ultimate shear capacity of the masonry panel, $G$ is the shear modulus, $A_{s}$ is the area of the cross-section. After this first branch, a branch with constant shear capacity characterizes the constitutive law until a point assumed halfway between the peak and the following point. A branch with degrading shear capacity follows the plateau. According to the Italian Building Code NTC08 [49], the degrading branch stops in correspondence of a value of shear capacity equal to $20 \%$ of the ultimate shear resistance and an angular deformation of $0.4 \%$. Finally, the ultimate drift is set equal to $1.0 \%$, as proposed in FEMA 356 [11].

In addition to the numerical approach described above, also an EF model with lumped plasticity is here studied for investigating the accuracy of the results provided in case of peculiar masonry wall geometries. In this model the in-plane non-linear response of masonry panels, both in case of piers and spandrels, is simulated by concentrating the whole non-linearity in three non-linear concentrated springs. Two non-linear springs are located at the edges of the masonry panels for describing the flexural behaviour, while the third one is located in the middle for simulating the shear response. Multi-linear constitutive laws were defined in accordance with FEMA 356 [11] to simulate both flexural and shear capacity of masonry panels.

\subsection{Non-linear Finite Element modelling of URM walls: micro-modelling approach}

The continuum micro-modelling approach used by Petracca et al. [37-38] is used in this work: both bricks and mortar joints are modelled with continuum 2D (plane-stress) finite elements, whose non-linear behaviour is described by means of a continuum damage model.

In order to simulate the different behaviours in tension and compression of both masonry components, the damage model is based on two damage indices $d^{+}$and $d^{-}$for tensile and compressive stress states, respectively. For a damage index equal to 0 the material is intact, while for a damage index equal to 1 the material is completely damaged. Then the damaged stress tensor is defined as follows: 


$$
\sigma=\left(1-d^{+}\right) \bar{\sigma}^{+}+\left(1-d^{-}\right) \bar{\sigma}^{-}
$$

where $\bar{\sigma}^{+}$and $\bar{\sigma}^{-}$are respectively the positive and negative parts of the effective (elastic) stress tensor $\bar{\sigma}$ :

$$
\bar{\sigma}=C: \varepsilon
$$

The split of the effective stress tensor in positive and negative parts is carried out as follows:

$$
\begin{array}{r}
\bar{\sigma}^{+}=\sum_{i=1}^{2}\left\langle\bar{\sigma}_{l}\right\rangle p_{i} \otimes p_{i} \\
\overline{\bar{\sigma}^{-}}=\bar{\sigma}-\bar{\sigma}^{+}
\end{array}
$$

where $\bar{\sigma}_{i}$ is the $\mathrm{i}^{\text {th }}$ principal stress of the elastic stress tensor, $p_{i}$ is its associated eigenvector, $\otimes$ represents the tensor product and $\langle x\rangle$ represents the positive part operator, defined as:

$$
\langle x\rangle= \begin{cases}0, & x<0 \\ x, & x \geq 0\end{cases}
$$

Two equivalent stresses $\tau^{+}$and $\tau^{-}$are introduced to identify "loading", "unloading" or "reloading" conditions, and they represent two surfaces in the principal stress space (2D plane-stress in this work). The two equivalent stresses are defined as follows:

$$
\begin{gathered}
\tau^{-}=H\left(-\bar{\sigma}_{\text {min }}\right)\left[\frac{1}{1-\alpha}\left(\alpha \bar{I}_{1}+\sqrt{3 \bar{J}_{2}}+k_{1} \beta\left(\bar{\sigma}_{\text {max }}\right)\right)\right] \\
\tau^{+}=H\left(\bar{\sigma}_{\text {max }}\right)\left[\frac{1}{1-\alpha}\left(\alpha \bar{I}_{1}+\sqrt{3 \bar{J}_{2}}+\beta\left(\bar{\sigma}_{\text {max }}\right)\right) \frac{f_{t}}{f_{c p}}\right] \\
\alpha=\frac{k_{b}-1}{2 k_{b}-1}
\end{gathered}
$$

where $\bar{I}_{1}$ is the first invariant of the effective stress tensor $\bar{\sigma}, \bar{J}_{2}$ is the second invariant of the deviatoric part of $\bar{\sigma}$, $\bar{\sigma}_{\max }$ is the maximum effective principal stress, $k_{b}$ is the ratio of biaxial compressive strength to uniaxial compressive strength, $f_{c p}$ is the compressive strength and $f_{t}$ is the tensile strength. The term $k_{1}$ is an input parameter calibrated to properly represent the dilatant behaviour of mortar joints, according to Petracca et al. [37-38]. Finally, the evolution of the tensile and compressive damage variables are governed by the tensile and compressive uniaxial laws depicted in Figure 4a and Figure 4b, respectively. The softening in tension and compression are determined also by the assumed values of the fracture energies $G_{f}^{+}$and $G_{f}{ }^{-}$.
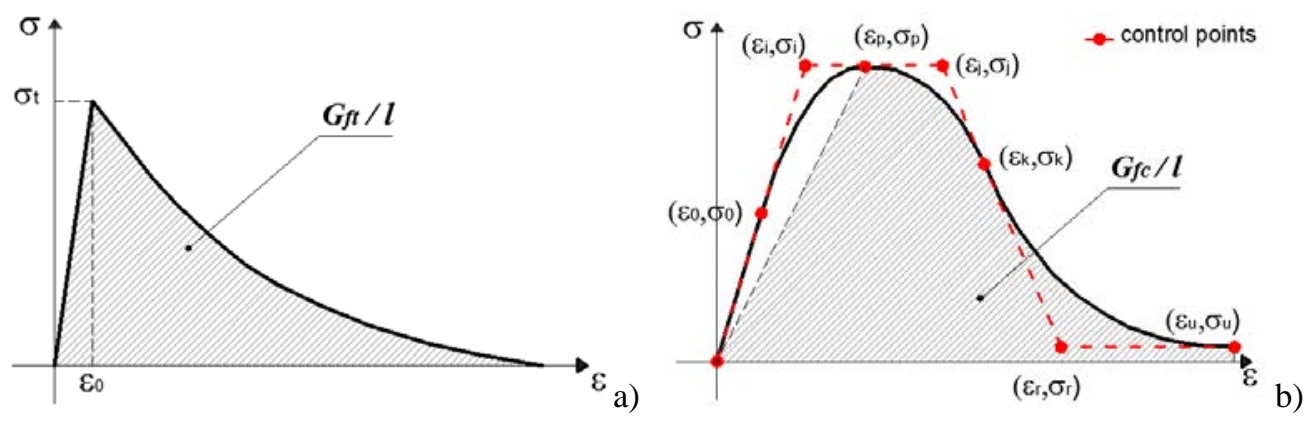

Figure 4: Tensile (a) and compressive (b) uniaxial constitutive laws for describing masonry behaviour in the micromodel [37-38].

\section{MECHANICAL CALIBRATION OF THE NUMERICAL MODELS}

In a first stage, the two mechanical models (EFM and FEM) were calibrated by simulating the experimental test carried out by Calvi and Magenes at the University of Pavia [25]. The mechanical parameters obtained for masonry and its components were then used in the numerical investigations described in Section 4.

The test specimen, which can be considered representative of existing buildings and traditional constructive technologies, is a two-storey building composed by 4 URM walls made of fired-clay bricks and lime mortar. Figure 5 shows the geometrical configuration of the tested prototype. As can be observed in the schemes of Figure 5, the connections between the walls were effective only between wall B and the transversal walls, while wall D was a completely independent structural system. Moreover, the floors consisted of isolated steel beams that gave only a 
light degree of coupling between the two longitudinal walls, simulating the presence of a flexible diaphragm. The interaction between the two longitudinal walls (wall B and D in Figure 5) was further minimized by the application of the same displacement history to both walls. Wall D can be then considered as an isolated resisting system.

During the experimental test, the building was first subjected to the vertical load corresponding to approximately $10 \mathrm{kN} / \mathrm{m}^{2}$ on each floor. Then, a quasi-static cyclic displacement history with increasing amplitude was applied to the top floor level, separately for the two longitudinal walls and with a constant distribution of forces between the two levels. The test stopped after reaching an ultimate displacement equal to about $0.023 \mathrm{~m}$. The maximum base shear reached by this wall was $149.70 \mathrm{kN}$. A more detailed description of the prototype geometry and the testing setup can be found in the extensive literature available on this experimental campaign [25, 54-56].

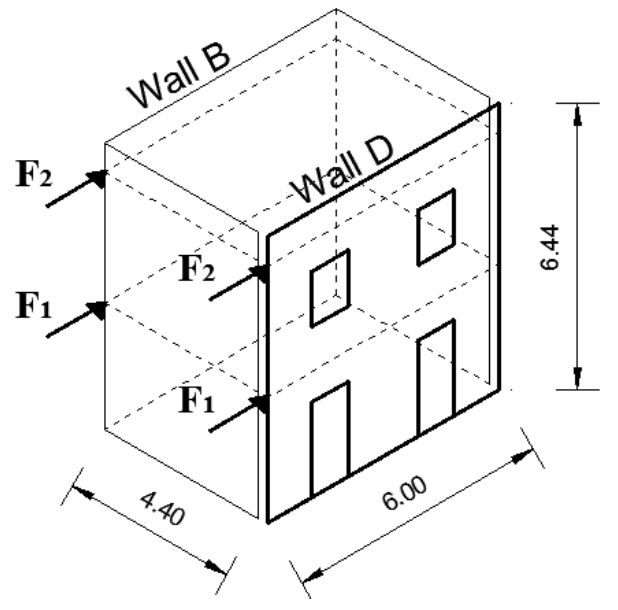

Figure 5: 3D view of the building prototype tested in Pavia [25].

The mechanical parameters of the two numerical models (EFM and FEM) were calibrated by considering the inplane behaviour of wall $\mathrm{D}$ since it constitutes an isolated resisting system, such as the $2 \mathrm{D}$ walls analysed in the following section. The implementation of the EF model follows the assumptions and criteria already described in section 2.1, so two EFM approaches were studied the one with spread plasticity [15] and the one with lumped plasticity. Both the geometrical criteria provided by Augenti [2] and Dolce [1] were accounted for the definition of piers effective height.

The mechanical properties of masonry were deduced by data available in literature [25, 54-56], Table 1 summarizes all the mechanical properties of masonry as homogeneous material adopted in the EFM numerical simulations. In particular, the wide scientific literature available for this test provided the Young's Modulus E, the weight density $\gamma$ and the compressive strength $f_{c p}$ of masonry. The remaining parameters, as in particular the tensile strength $f_{t}$ of masonry, were derived using calibration procedures supported by the experimental and numerical data provided by previous numerical simulations available in literature [57-58].

The FE model was defined as a two-dimensional micro-model implemented in Kratos Multiphysics [59-60], and using GID (C) [61] as pre and post-processor. The mechanical behaviour of units and mortar joints was simulated separately using the parameters presented in Table 2. As in the case of the EF model, the mechanical parameters were derived from data available in literature [25, 54-56], as in particular compressive strength $f_{c p}$ and the weight density $\gamma$ of both masonry components [54]. The correlation between the two mechanical models was verified by referring to a system of two components (1 brick and 1 mortar joints) working in series and submitted to a compression force. In this way, it was possible to derive the elastic properties of masonry, as a homogenous material, from the ones of the single components.

Finally, the boundary and loading conditions simulated the testing setup. In both the modelling approaches, the actual stiffness of the diaphragms was accounted as well as the presence of non-reinforced spandrels. All the models were subjected to non-linear static analyses with displacement control. It is worth noting that the numerical simulations considered a monotonic loading history, differently from the experiment where a cyclic loading history was applied to specimen. Because of this choice, the damage can be partially reproduced by the numerical models under consideration.

Figure 6 shows the comparison between the numerical predictions provided by EF and FE models and the experimental data reported in [25], the latter expressed as cyclic curve and the corresponding envelope. The 
numerical curves refer to the reference FE model (FE micro-model), but also to both the EF models under consideration, the model with fiber discretization of the macro-elements (EFM fiber) and the one with lumped springs (EFM Lumped Hinges). The results obtained show a satisfactory agreement between the numerical and experimental data, since the numerical capacity curves predict well the envelope of the experimental curve. The prediction of the maximum base shear is also satisfactory, showing errors lower than $10 \%$ both in the case of EFM and FEM $\left(V_{\max }=155.50 \mathrm{kN}\right)$. A very good agreement is found in the prediction of the elastic stiffness, as shown in Figure 6.

Table 1: Mechanical properties for the numerical simulation of the test by Calvi and Magenes [25] with EFM.

\begin{tabular}{lllllll}
\hline $\mathrm{E}[\mathrm{MPa}]$ & $v[-]$ & $\gamma\left[\mathrm{kN} / \mathrm{m}^{3}\right]$ & $f_{c p}[\mathrm{MPa}]$ & $\varepsilon_{\mathrm{c} 0}[-]$ & $f_{t}[\mathrm{MPa}]$ & $\varepsilon_{0}[-]$ \\
\hline 1490.0 & 0.20 & 18.00 & 6.20 & 0.0010 & 0.18 & 0.000018 \\
\hline
\end{tabular}

Table 2: Mechanical properties for the numerical simulation of the test by Calvi and Magenes [25] with FEM.

\begin{tabular}{llllllll}
\hline Component & $\mathrm{E}[\mathrm{MPa}]$ & $v[-]$ & $\gamma\left[\mathrm{kN} / \mathrm{m}^{3}\right]$ & $f_{c p}[\mathrm{MPa}]$ & $f_{\mathrm{t}}[\mathrm{MPa}]$ & $\mathrm{G}_{\mathrm{fc}}[\mathrm{N} / \mathrm{mm}]$ & $\mathrm{G}_{\mathrm{ft}}[\mathrm{N} / \mathrm{mm}]$ \\
\hline Brick & 6000.0 & 0.20 & 16.14 & 9.00 & 1.26 & 20.0 & 0.05 \\
\hline Mortar & 300.0 & 0.20 & 20.00 & 4.33 & 0.04 & 40.0 & 0.0025 \\
\hline
\end{tabular}

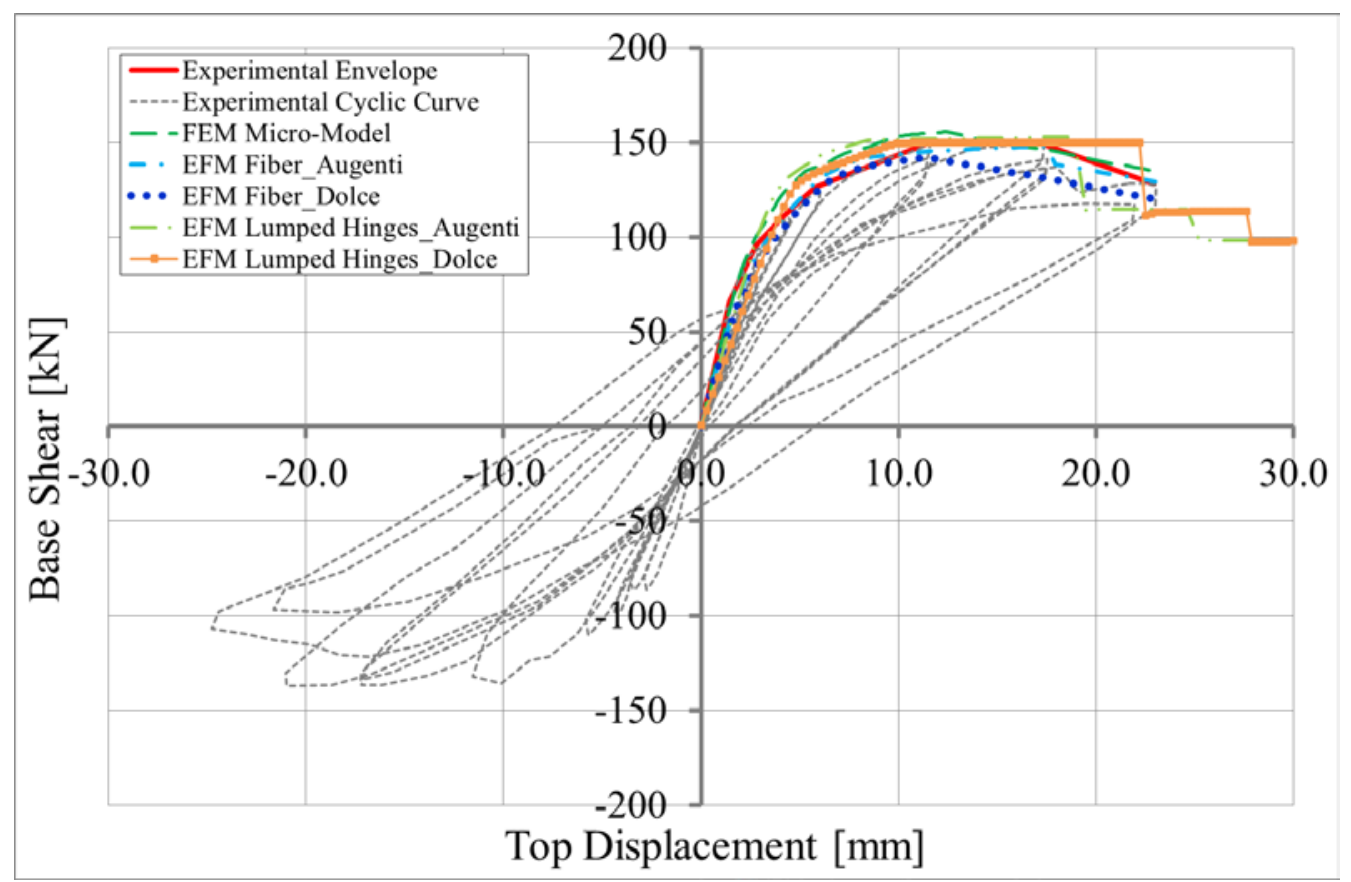

Figure 6: Comparison between experimental and numerical capacity curves.

Regarding the damage patterns, the experimental test showed that the spandrels failed first, and the initial concentration of damage in these elements induced a reduction of the coupling effect among the piers. Compression damage also appeared at the base of the first level piers. However, the phenomenon that governed the ultimate capacity of the prototype was the shear cracking of the central pier. A strong concentration of damage was found in the lower floor central pier, as shown in Figure 7a. An analogous performance is predicted by all the numerical models as reported in Figure 7b, Figure 7c and Figure 7d that describes the damage patterns predicted by FE and EF 
models respectively. In the case of the two EF models, the damage pattern induced by flexural and shear are presented separately in the two diagrams of Figure 7c and Figure 7d. For these models, the first diagram shows the distribution of flexural damage obtained with the fiber element model. The second diagram presents the damage pattern of the lumped shear springs. The combination of the information provided by both diagrams defines the complete damage pattern predicted by the EF model.
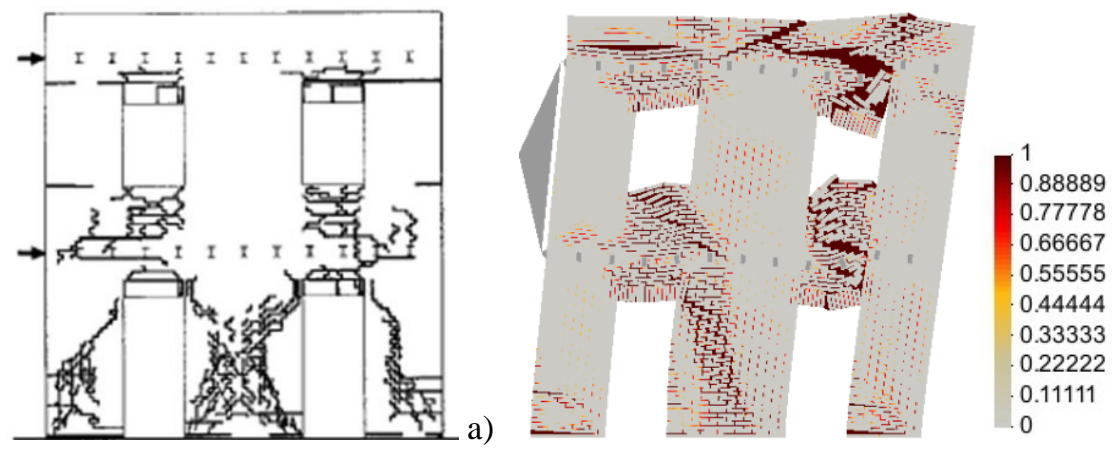

b)
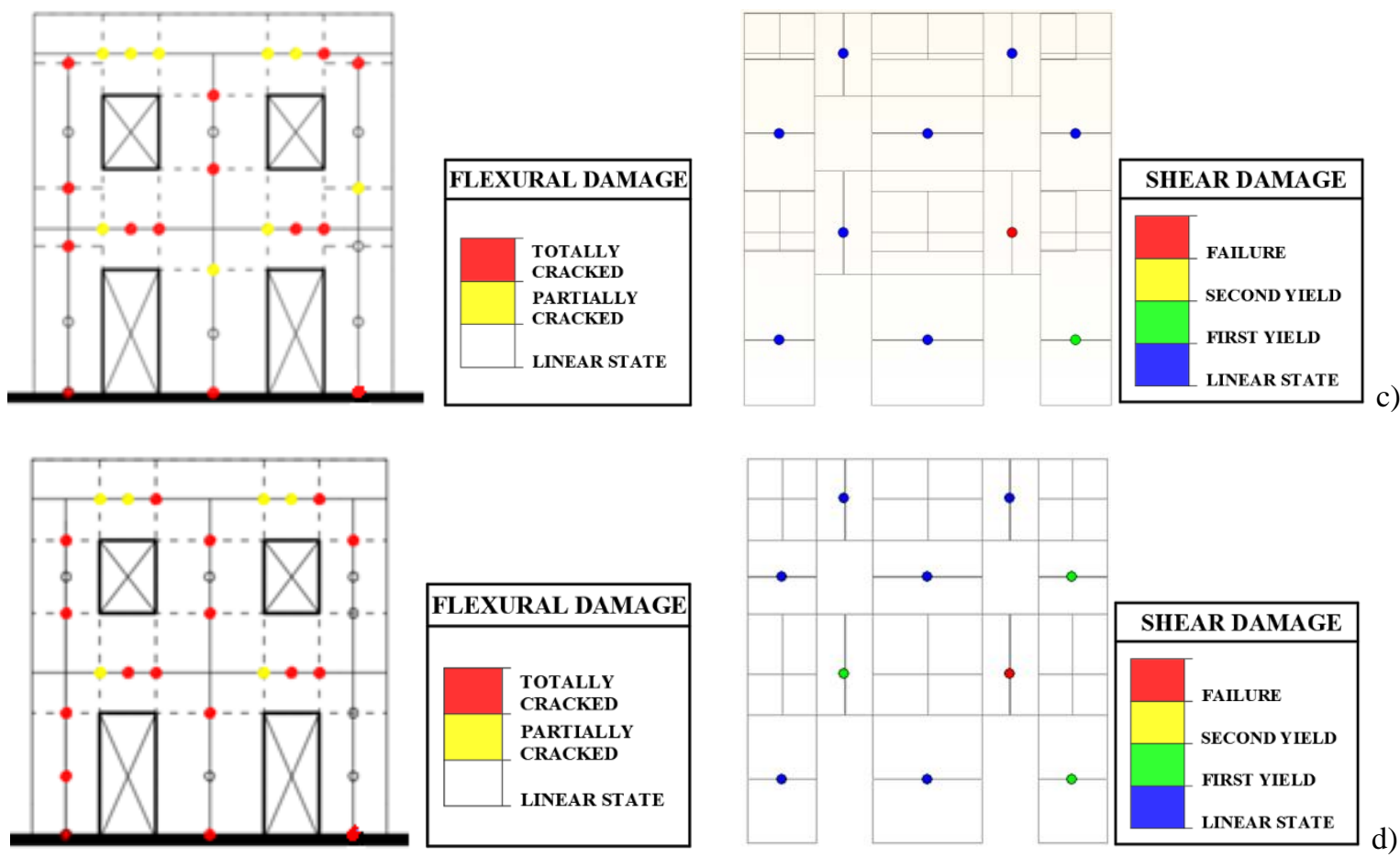

d)

Figure 7: Comparison of Damage Status: a) experimental results [25], b) FEM, c) EFM according to Dolce's criterion and d) EFM according to Augenti's criterion (flexural and shear damage).

Both models predict correctly the concentration of damage in the lower part of the wall and the shear collapse of the first level spandrels as first failure mechanisms. However, there is a difference in the prediction of Pier 2 failure between the FEM and the EFM. The FE model predicts well the mixed flexure-shear failure of Pier 2 observed in the test, while the two EF models show a predominant flexural failure. This difference can be explained with the strength domains, shown in Figure 8. The flexural and the shear capacities of Pier 2 are very similar for the axial load $(175 \mathrm{kN})$ recorded when Pier 2 started failing. For this reason, in the experiment the initial horizontal flexural cracks were followed by the activation of the shear failure mechanism. This failure is predicted well by the continuum model which follows the consecutive activation of flexural and shear mechanisms. In the case of the EFM, instead the first activation of the flexural mechanism at the base unload the element prevents the activation of the shear failure. 

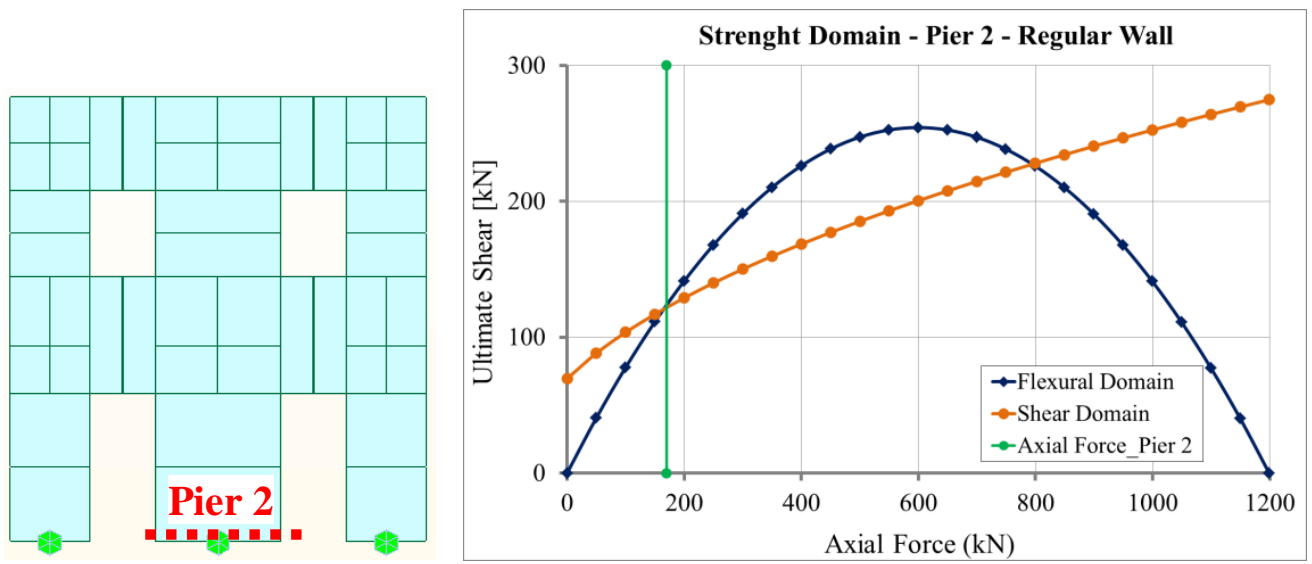

Figure 8: Strength domains for the central pier at first floor of the wall D.

\section{INVESTIGATION OF EQUIVALENT-FRAME MODELS IN NON-LINEAR FIELD}

The numerical investigation presented herein is aimed at evaluating the accuracy of the EFM for simulating URM existing constructions. This study started in the linear range [18], where the modelling accuracy of EFM was tested for single two-storey URM walls with varying geometry by comparing the results provided by EFM and FE models. Non-dimensional parameters were introduced to measure the influence of the walls geometry on the modelling accuracy of EFM [18]. This led to the definition of specific limits of applicability of the EFM approach and to the identification of critical geometries for which EFM provided unrealistic predictions.

The study is here extended to the non-linear field, by comparing the results provided by the EF model and a FE micro-model for the most critical geometries identified in the linear field for regular walls. These models are studied with non-linear static analyses under the same boundary, mechanical and loading conditions. The results obtained are then compared in terms of global capacity curves and damage mechanisms. In particular, the comparative study focuses on the maximum shear capacity provided by both EFM and FEM, with the intent to verify the capacity of the simplified models in predicting the effective resistance of masonry shear walls with respect to more refined models. The differences between the predictions provided by the two modelling approaches are considered a measure of the EFM modelling accuracy. In this way, the limits identified for EFM in linear field [18] are verified also in the non-linear field in the case of regular walls.

All the EF approaches presented in the following sections have been implemented in the software Midas GEN () [44] by assuming the mechanical model and the theoretical assumptions described in section 2.1. The FE model was implemented in Kratos Multiphysics [59-60] as a two-dimensional micro-model based on the theory described in section 2.2.

As explained in Section 3, the FE micro-model is taken as a reference to measure the EFM modelling accuracy. Its reliability is guaranteed not only by the high level of detail that characterizes this FEM approach, but also by its previous calibration reported in Section 3. Moreover, many numerical simulations of experimental tests $[14,57,58]$ and existing buildings [62,63] available in the scientific literature provide further confirmation for the accuracy of FEM in the structural modelling of URM structures.

\subsection{Models selection and mechanical characterization}

In the first step of the research [18], a wide set of regular geometries was tested in the linear field by means of equivalent linear static analyses. All the geometries were obtained from the same reference scheme, which replicates the geometrical configuration of the URM wall tested by Calvi and Magenes [25] (Figure 5), by varying separately the height and the width of the openings. The reference geometry was a two-storey wall with global dimensions $6.00 \times 6.43 \mathrm{~m}^{2}$ and a constant thickness of $0.30 \mathrm{~m}$. Figure 9 summarizes the geometrical schemes assumed for the sensitivity analysis carried out in linear field [18]. The picture also describes the criterion adopted for deriving each geometry from the reference one. More specifically, a decreasing height was assumed to derive the schemes along the rows of Figure 9 while a decreasing width characterizes the schemes along the columns with respect to the reference scheme (the scheme in red square in Figure 9). 
For all geometries, the percentage differences between the EFM and FEM results were recorded to obtain a measure of the EFM accuracy. A set of ad hoc non-dimensional parameters, introduced in Siano [18], expressed the EFM modelling accuracy as a function of the geometry of the wall. By using these non-dimensional parameters, it was possible to identify specific limits of applicability of EFM to regular masonry walls. More specifically, the parameters introduced in Siano [18] provided a numerical criterion to identify the geometries that can be accurately described by EFM.

Starting from the linear results, a few critical geometries were selected to complete the comparative study in the non-linear field. The first step was to establish a reference for estimating the modelling performance of EFM and FEM in non-linear field and, at the same time, to guarantee a mechanical equivalence between the two modelling approaches. With this aim the reference scheme (scheme within the red square in Figure 9) was preliminarily tested by comparing non-linear EF and FE models with the experimental results, the results provided by the numerical models for this scheme are reported in Section 3. Then the accuracy of EFM results was estimated by testing schemes characterized by larger or smaller opening widths or heights (i.e. by choosing schemes located along the dotted blue row or the dashed green column of Figure 9). Finally, the scheme providing the worst results in the linear field (the scheme in light blue dot and dashed line) was also tested in order to confirm the limits of applicability identified for EFM in the linear analyses in case of extreme geometries. The schemes of Figure 9 included in the squares represent the geometries selected for the numerical validation discussed in the following.

Since the linear analyses [18] demonstrated a strong influence of the effective height of the piers on the accuracy of the EFM results, in the non-linear analyses presented here, the sample cases were tested by following the two most common criteria for EFM implementation. More specifically, the EF models were defined alternatively with the criteria provided by Dolce [1] and by Augenti [2], for the definition of the effective height of the piers. The comparison of both EF models with the FEM predictions allowed also to assess the accuracy of these criteria for the non-linear analysis of URM walls.

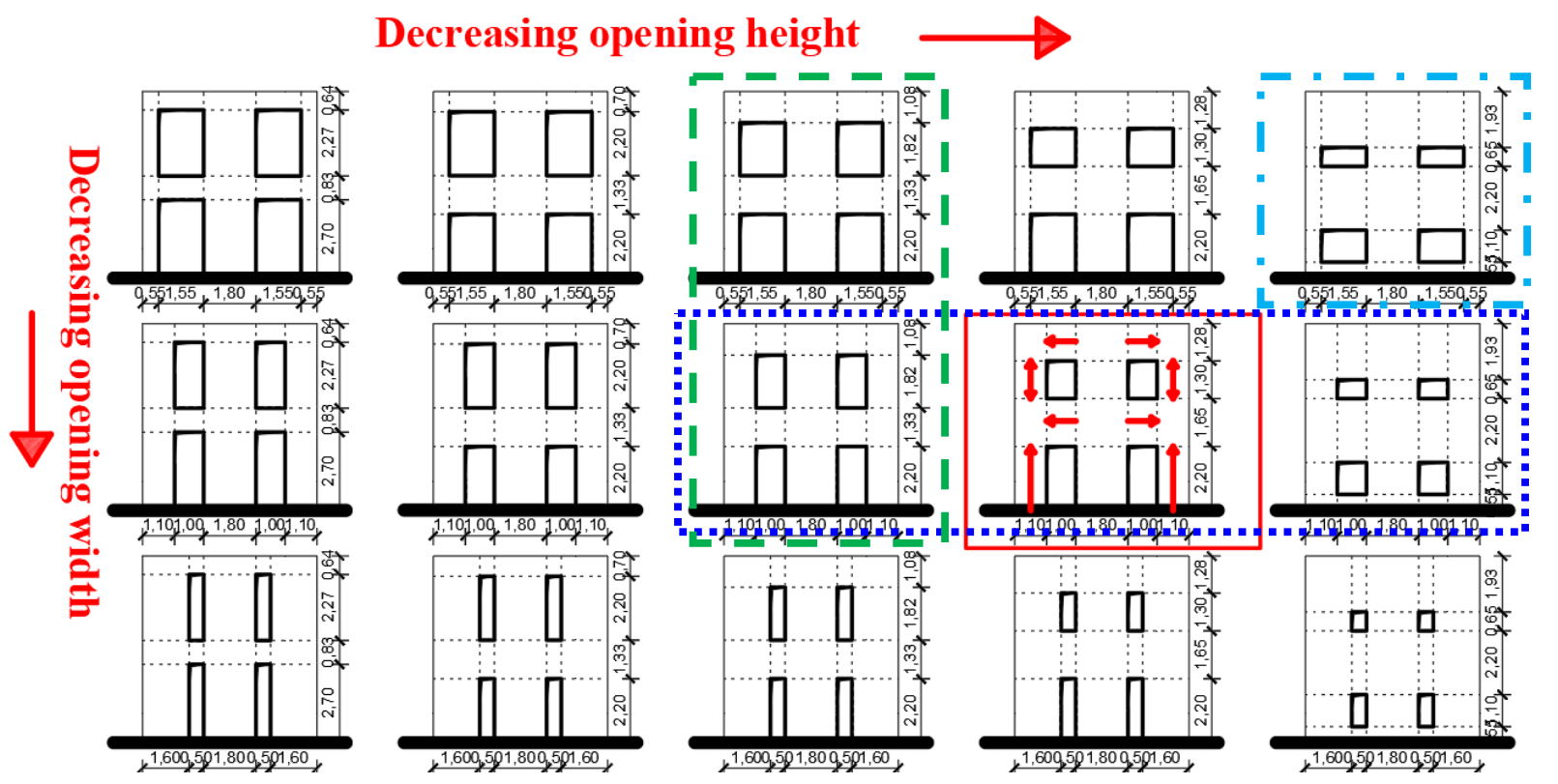

Figure 9: Selection of models for sensitivity analyses in linear field.

Figure 10 shows the geometrical properties of the four additional sample walls tested in the non-linear field. Although they are limit cases in the set of models discussed in [18], all the selected configurations correspond to piers-to-spandrels geometrical relations that can be found in old buildings (often together with geometrical irregularities, that lead to even more critical configurations). These cases are normally analysed by practitioners with EF models, without having any evidence of their accuracy for such critical cases. For this reason, it is worth comparing EFM and FEM non-linear results for walls in Figure 10.

All the sample schemes were subjected to non-linear static analyses under the same mechanical, boundary and loading conditions. The non-linear analyses used the mechanical characterization obtained in the simulation of the Pavia test (Section 3), so the same mechanical properties reported in Table 1 and Table 2 were considered for the EF and the FE model, respectively. Again, the loads were applied in two stages: first the vertical (self-weight and a 
constant load of $15.90 \mathrm{kN} / \mathrm{m}$ per floor) and then the horizontal loads with a monotonically increasing law with a constant distribution along the wall height.
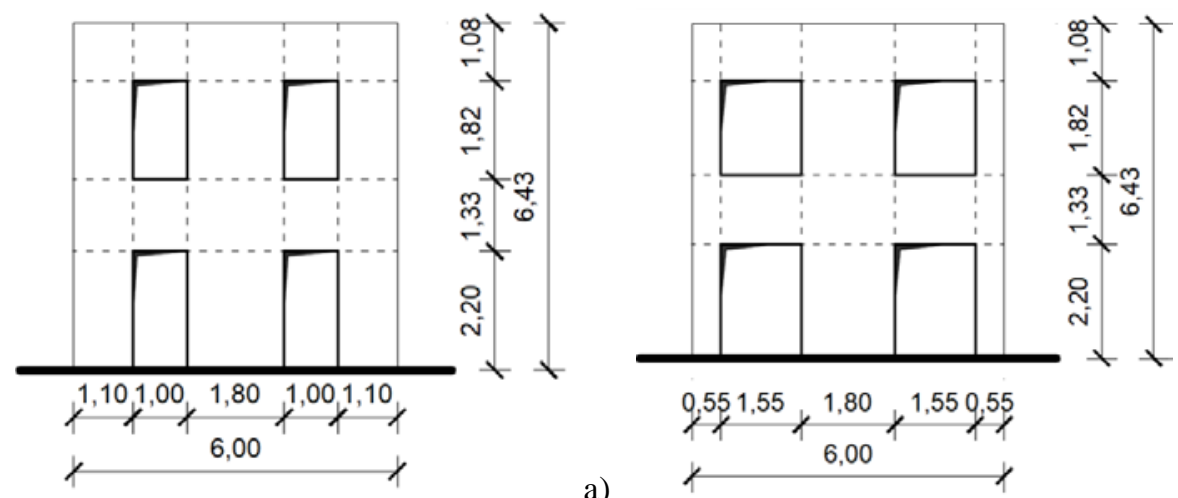

a)
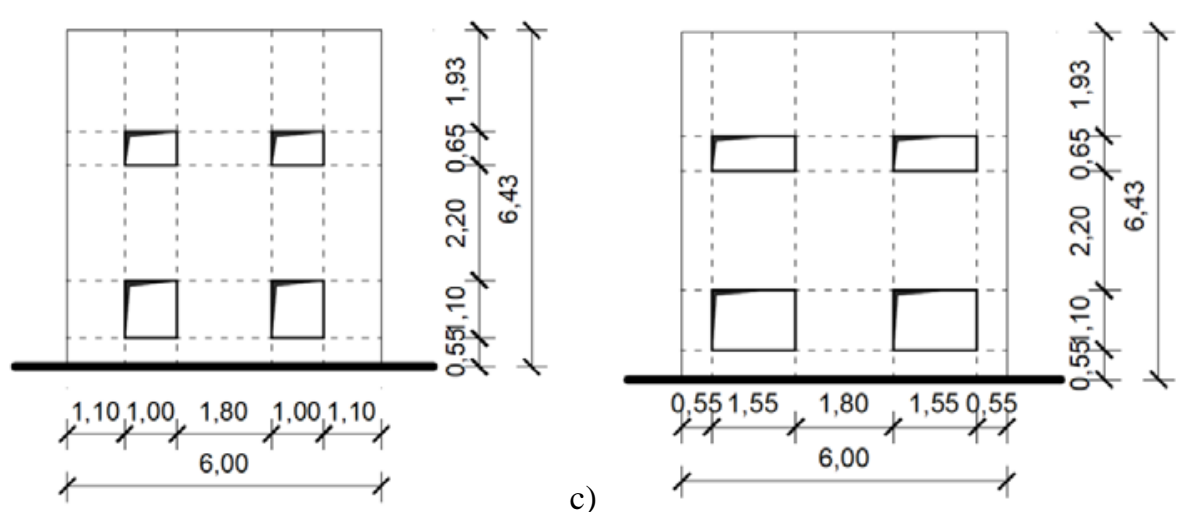

b)

c)

d)

Figure 10. Geometrical configuration of URM regular walls modelled in non-linear field A: a) Scheme A, b) Scheme B, c) Scheme C and d) Scheme D.

\subsection{Discussion of the results}

The first regular scheme tested is the scheme A (Figure 10a). Figure 11 reports the results obtained for scheme A in terms of global capacity curves obtained with the EF and FE models. Concerning the EFM approach, the results include the two aforementioned criteria for the definition of the pier effective height, provided by Dolce [1] and Augenti [2], and the two numerical approaches described in section 2.1. For the selected geometry, different performances characterize the two EFM approaches with respect to the FE micro-model. More specifically, a satisfactory matching can be observed for the fiber EF model, while a lower accuracy affects the EF models implemented with lumped non-linear springs. In the case of the fiber EF models, percentage differences lower than $20 \%$ characterize the prediction of the maximum base shear $\left(V_{\max }=58.66 \mathrm{kN}\right.$ with EFM according Augenti's criterion and $V_{\max }=61.07 \mathrm{kN}$ according Dolce's one) with respect to the FEM prediction $\left(V_{\max }=72.78 \mathrm{kN}\right)$. The two EF models with concentrated hinges slightly overestimate the global shear capacity of the wall ( $V_{\max }=89.42 \mathrm{kN}$ for Dolce's model and $V_{\max }=88.00 \mathrm{kN}$ for Augenti's model) exceeding of about 23\% the FEM estimation.

Focusing on the post-peak behaviour, all the capacity curves provides a plateau with a slight softening only in the FEM curve.

The comparison of the modelling approaches involves also the predicted failure mechanisms. Figure 12, Figure 13 and Figure 14 show the damage patterns provided for the case A by the three numerical models, respectively. The EFM approaches predict mainly the flexural mechanisms. This result is partially confirmed by the FE model that shows a strong concentrations of flexural cracks in almost all the piers. All the models predict a strong concentration of damages in the spandrels of both levels, but a worse matching characterizes the prediction of shear mechanisms in the central piers that is evident in the FE model and not predicted at all by any EF model. Only in the case of EF models with concentrated springs, it is possible to observe a good prediction of the concentration of shear failure in the right spandrel at first level. 

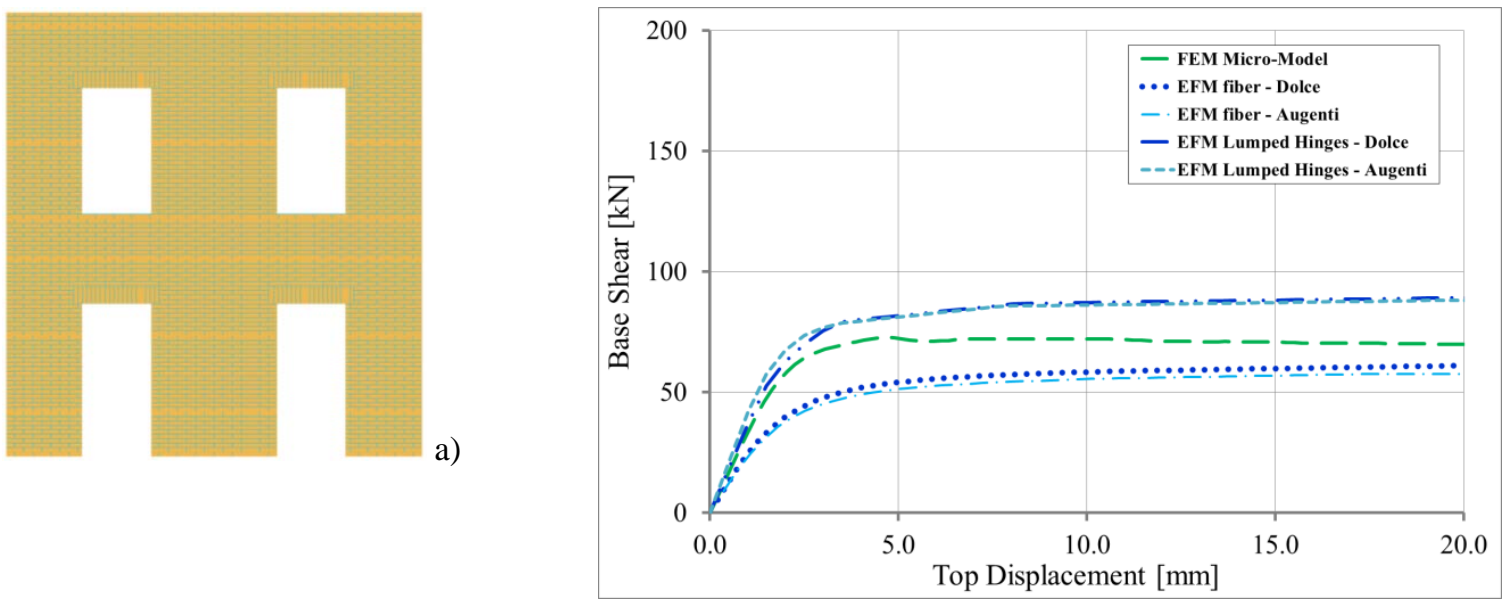

Figure 11. Micro-model of scheme A (a) and comparison of EFM and FEM capacity curves.

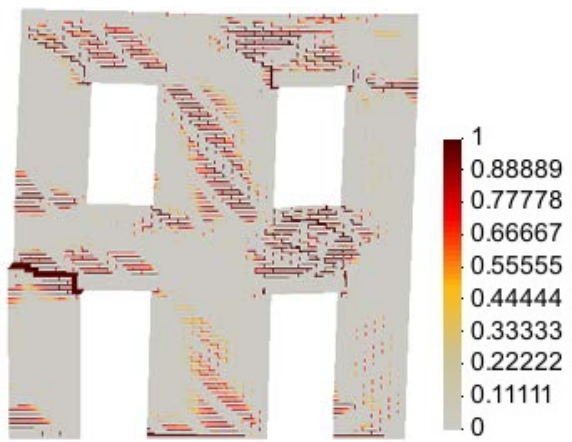

Figure 12. Damage patterns of scheme A according to the FE micro-model.
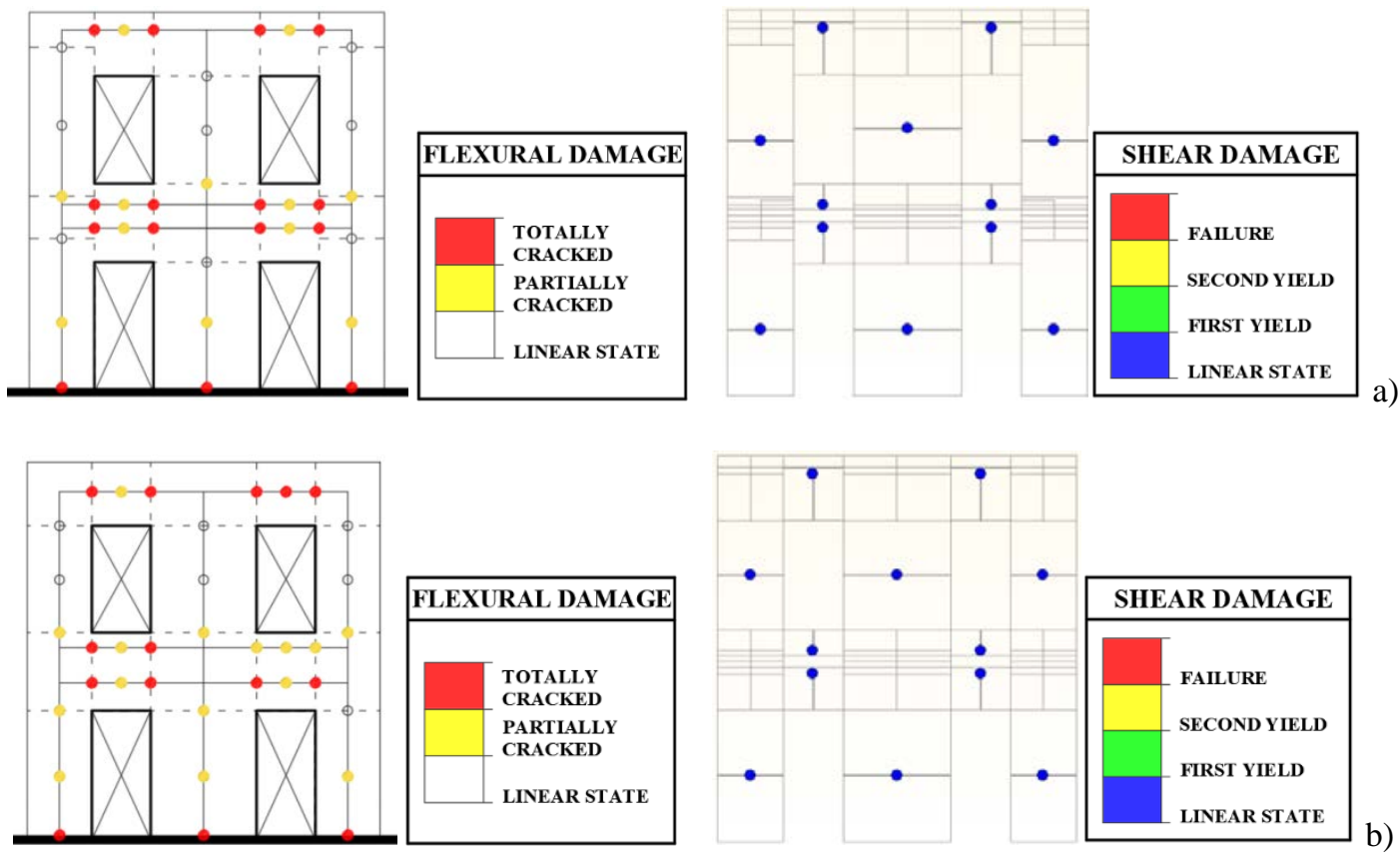

b)

Figure 13. Damage patterns of scheme A according to the fiber EFM with Dolce's (a) and Augenti’s model (b). 

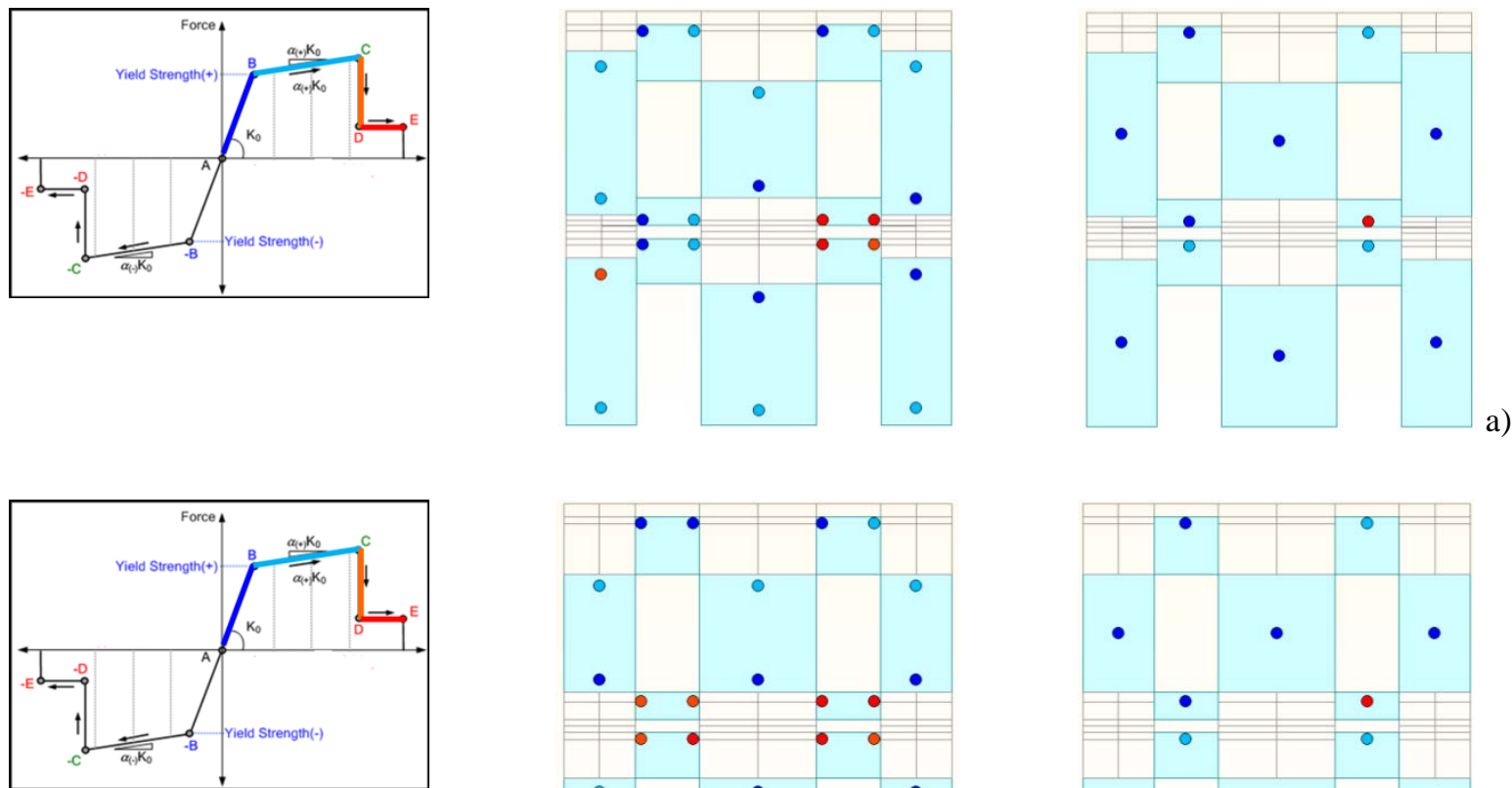

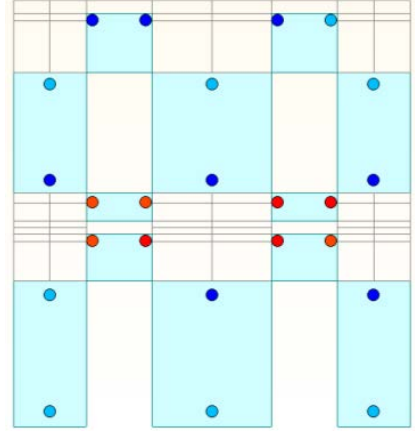

Flexural Damage

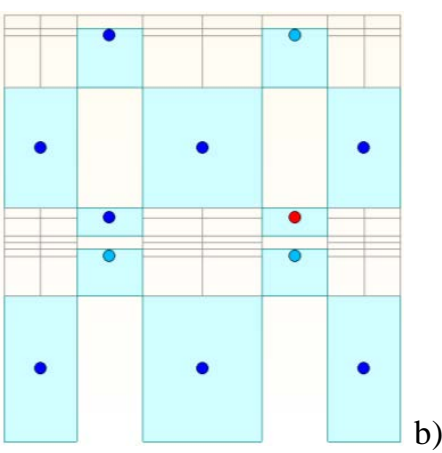

Shear Damage

Figure 14. Damage patterns of scheme A according to the EFM with concentrated hinges defined according to Dolce's model (a) and Augenti's model (b).

Regarding the scheme B of Figure 10b, Figure 15b shows the comparison of the capacity curves provided by the EF models and the corresponding FE micro-model. Low differences with respect to FEM results characterize all the fiber EF models for the case B. The ultimate shear capacity predicted for the scheme B by the two EF fiber models, which give almost coincident results, is slightly higher than in the FE model. The predicted peak point differs by about $+4.50 \%$ between the EF model defined according to Dolce's criterion and FEM, while the model defined according to Augenti's criterion provides a maximum base shear that differs of about $+9 \%$ with respect to the FEM result. These models show a very good agreement in the prediction of the overall wall stiffness with respect to the FEM results. The elastic branches are in fact almost coincident for all the models.

Greater differences characterize the EF models defined with concentrated hinges with respect to the FEM results. For these models, the prediction of the overall shear capacity differs of about $22 \%$ with respect to the FEM predictions. The two EF models present also a slight lower stiffness with respect to the remaining models.

Figure 16, Figure 17 and Figure 18 show the damage patterns predicted by all the numerical models under consideration. Both EF and FE models confirm the prevalence of a flexural behaviour. In fact, all the panels show a prevalence of flexural cracks, in particular in the case of the EF models with fiber discretization. For these models, all the shear springs maintain an elastic behaviour until the end of the analysis. Some differences can be observed in the central pier, although for this element all the EF models are able to predict the high damage state predicted by the FE model. All models confirm a concentration of damage in the spandrels, but among the two EFM approach only the one with concentrated hinges predicts partially the shear damage of the spandrels. 

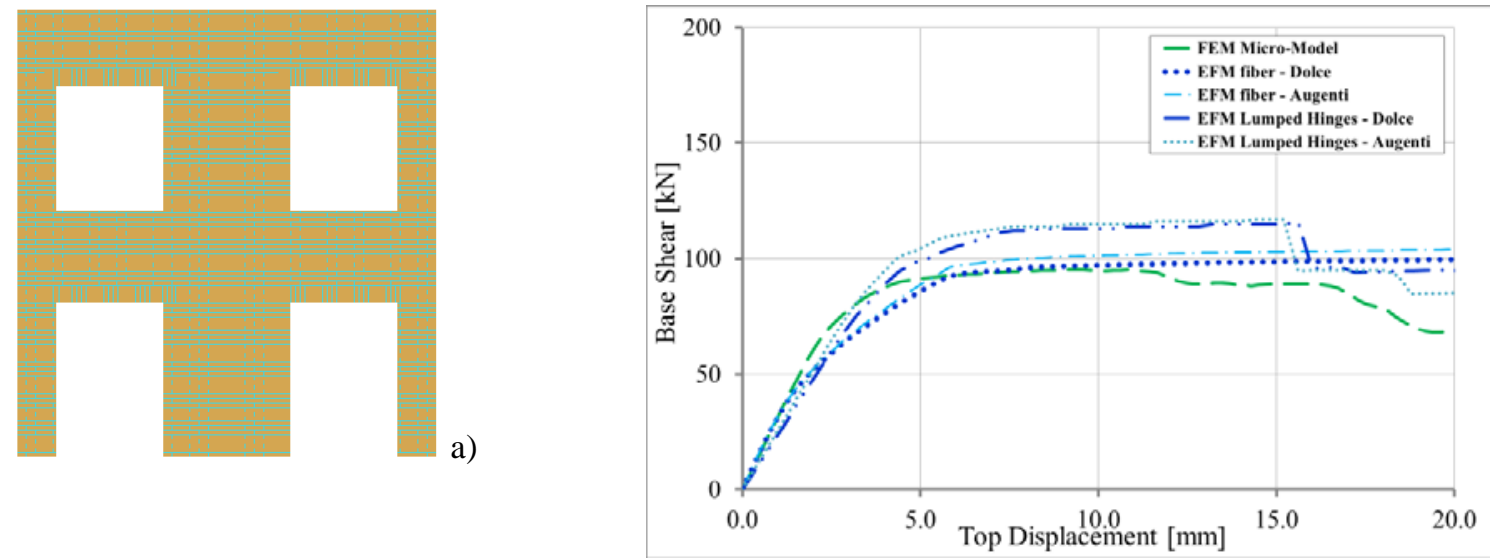

b)

Figure 15. Micro-model of scheme B (a) and comparison of EFM and FEM capacity curves (b).

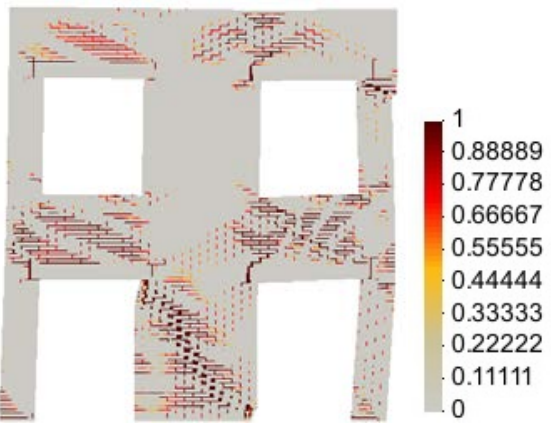

a)

Figure 16. Damage patterns of scheme B according to the FE micro-model.

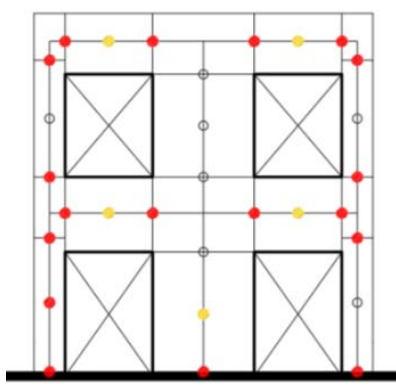

FLEXURAL DAMAGE
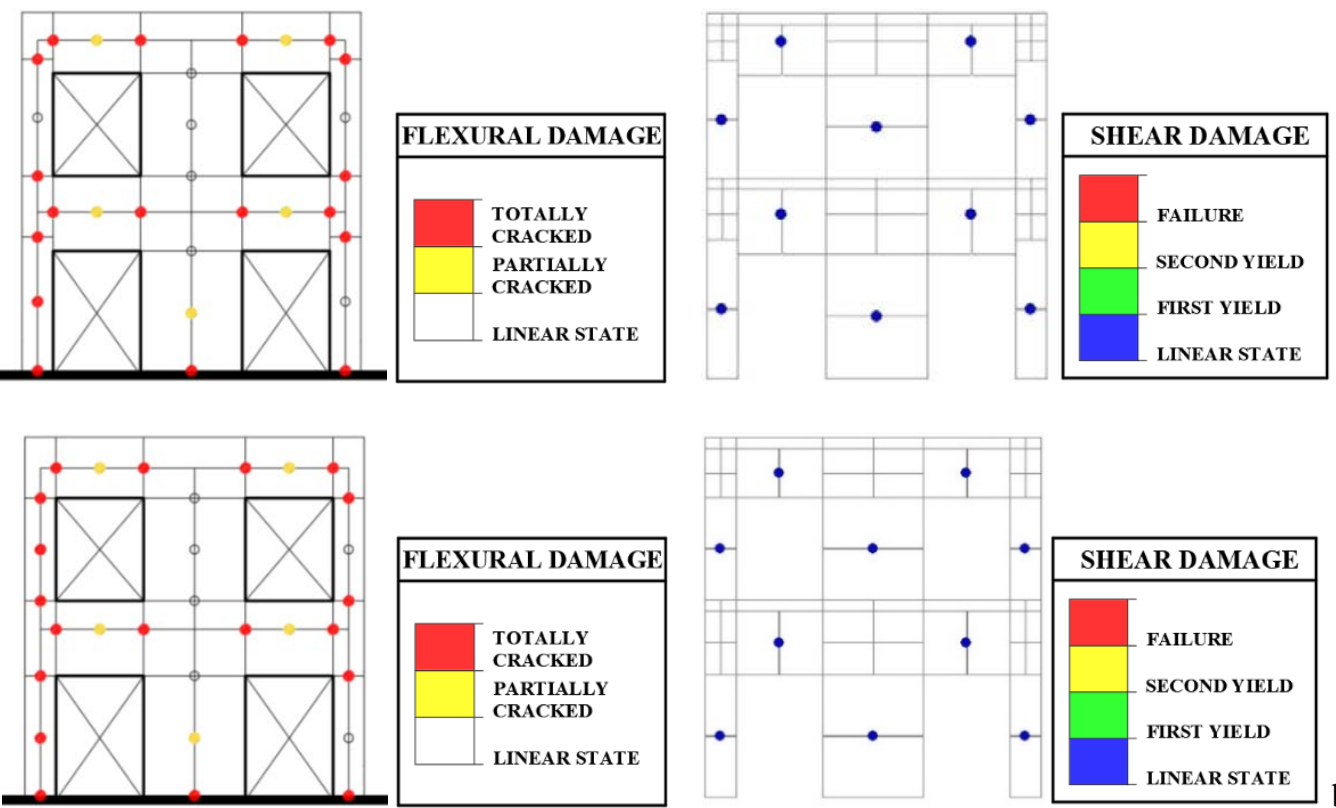

a)

Figure 17. Damage patterns of scheme B according to the fiber EFM with Dolce's (a) and Augenti's model (b). 

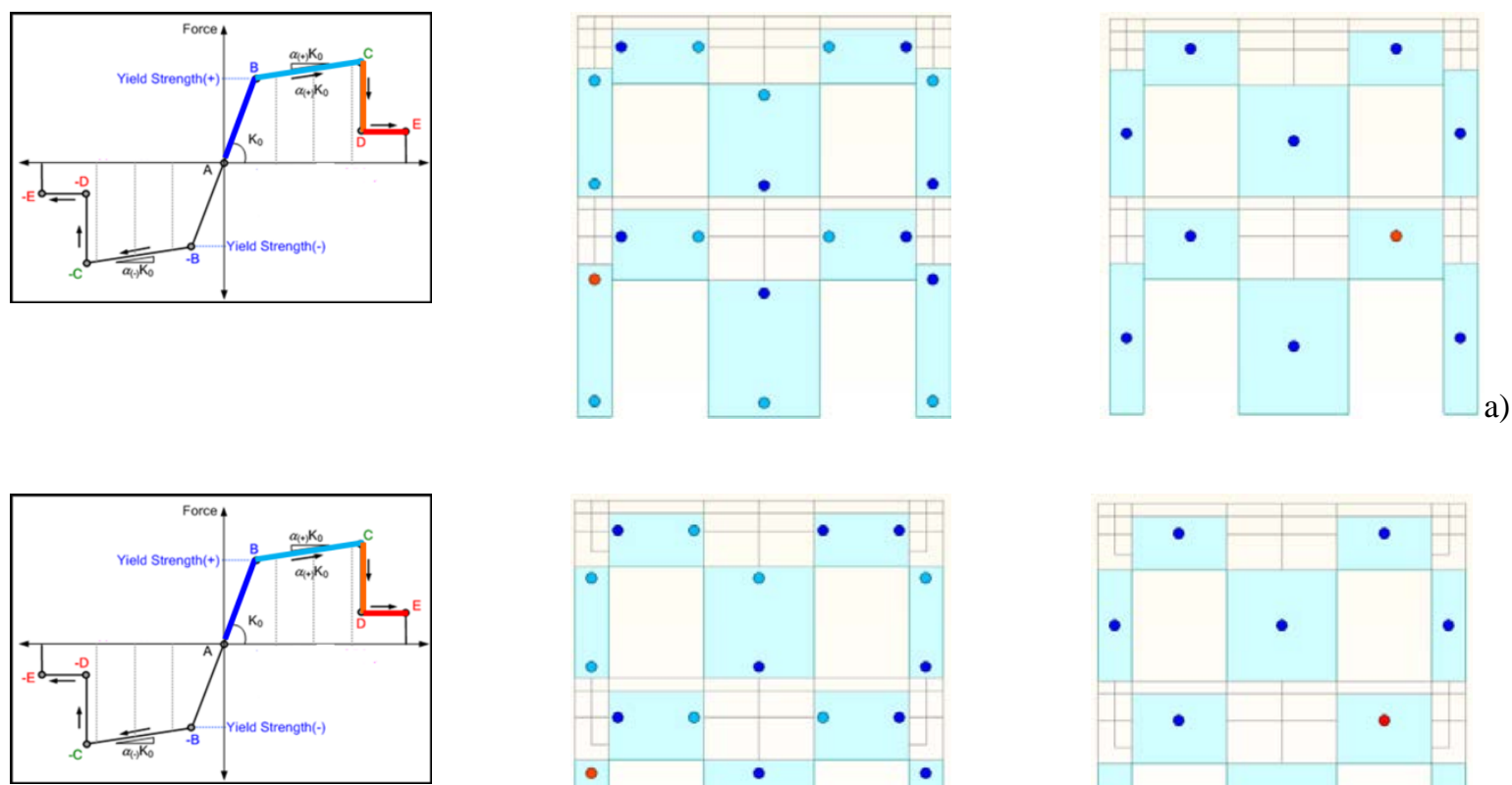

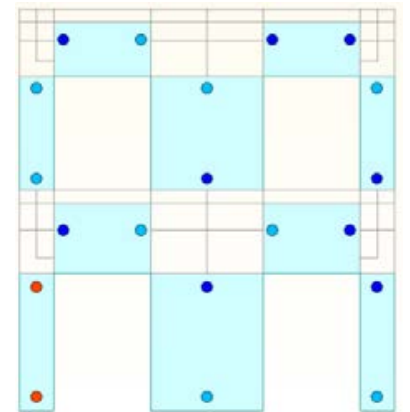

Flexural Damage

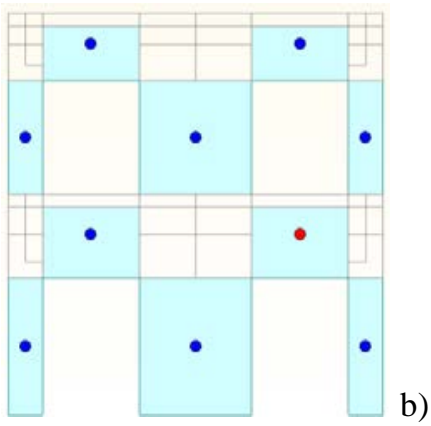

Shear Damage

Figure 18. Damage patterns of scheme B according to the EFM with concentrated hinges defined according to Dolce's model (a) and Augenti's model (b).

The third scheme (Figure 10c) showed a higher difference between the EFM and FEM results when it was analysed in the linear field [18]. For this scheme, Figure 19b reports the capacity curves obtained by using both nonlinear EF and FE models. The comparison of the capacity curves confirms the remarkable differences between the two modelling approaches. However, a slight reduction of these differences can be observed in the non-linear results for the EF models with fiber discretization. In particular, the nonlinear EF model defined according to Dolce's criterion provides the lowest difference with respect to FEM in the prediction of the ultimate shear capacity, namely a difference of about $+14 \%$ for the fiber model and $32 \%$ for the model with concentrated hinges. Moreover, the shape of the capacity curve provided by the fiber model is perfectly compatible with the curve provided by FEM, both in the elastic branch and in the non-linear part. The EF model based on Augenti's criterion shows larger differences, with respect to the FEM results, overestimating the ultimate shear capacity of the wall by $+30 \%$ in the fiber model and $41 \%$ in the model with concentrated hinges.

The description of the post-peak behaviour provided by the two fiber EF models is more similar to the behaviour described by the FE model, in particular in the case of the Dolce's approach since the softening branch follows the same evolution described by the FEM curve. A more stepped path characterizes the post-peak branch of the two EF models with lumped hinges due to the progressive plasticization of hinges and sudden reductions of the shear capacity. The two EF models with lumped hinges show a better agreement with FEM in the description of the deformation capacity of the wall, even though they overestimate the capacity both at the peak and in the post-peak range.

Figure 20, Figure 21 and Figure 22 show the damage patterns provided by the three numerical models for case $\mathrm{C}$ (Figure 10c). In this case, the fiber EF model defined according to Augenti's criterion provides results more compatible with the FEM predictions. In fact, the EFM model defined according to this criterion is able to identify distributions of both flexural and shear damage in piers and spandrels that closely match the FEM results. The concentration of shear cracks in the spandrels and in the lower piers is predicted well by this EF model. Conversely, a slight underestimation of the damage is provided by the EF model defined according Dolce's criterion. An 
inverted performance characterizes the two EF models with concentrated hinges, since for these model the damages are generally underestimated by the Augenti's scheme and better predicted by the Dolce's one.
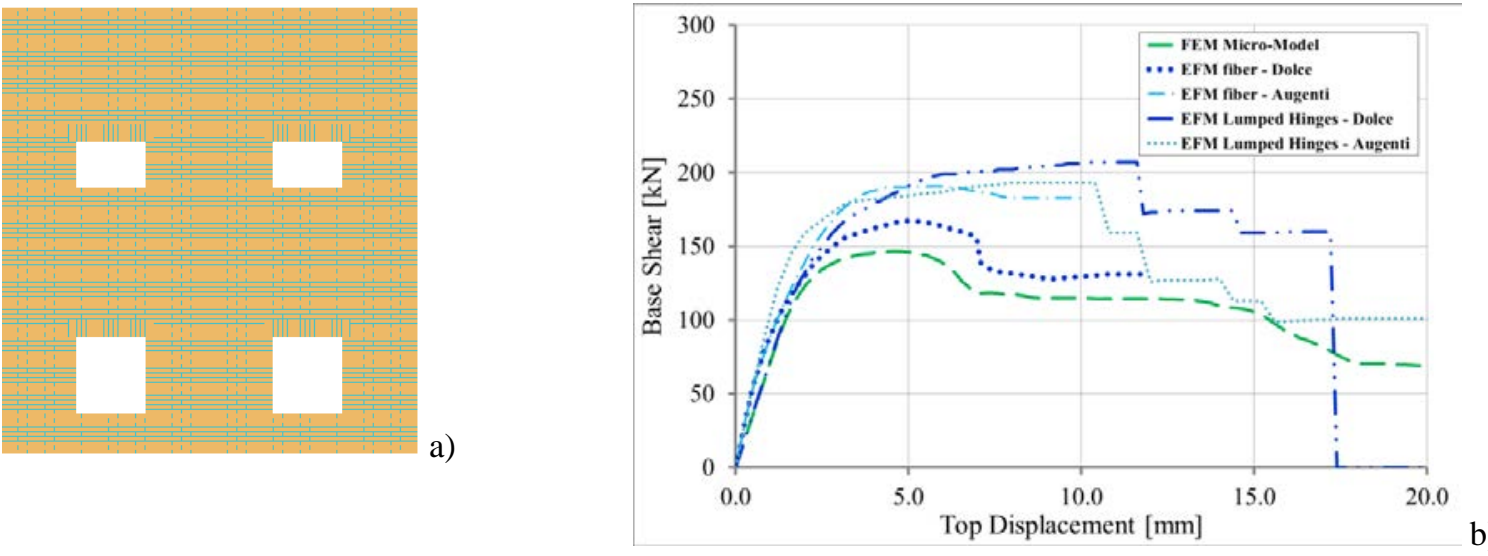

Figure 19. Micro-model of scheme C (a) and comparison of EFM and FEM capacity curves.
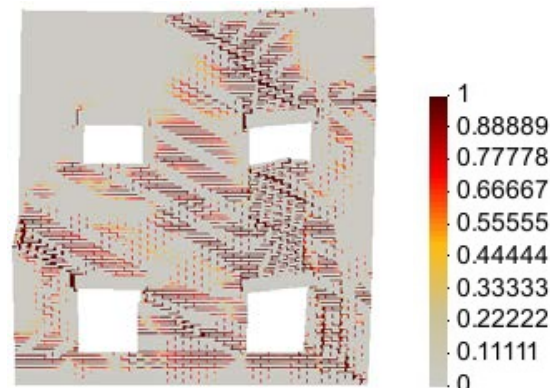

Figure 20. Damage patterns of scheme C according to the FE micro-model.
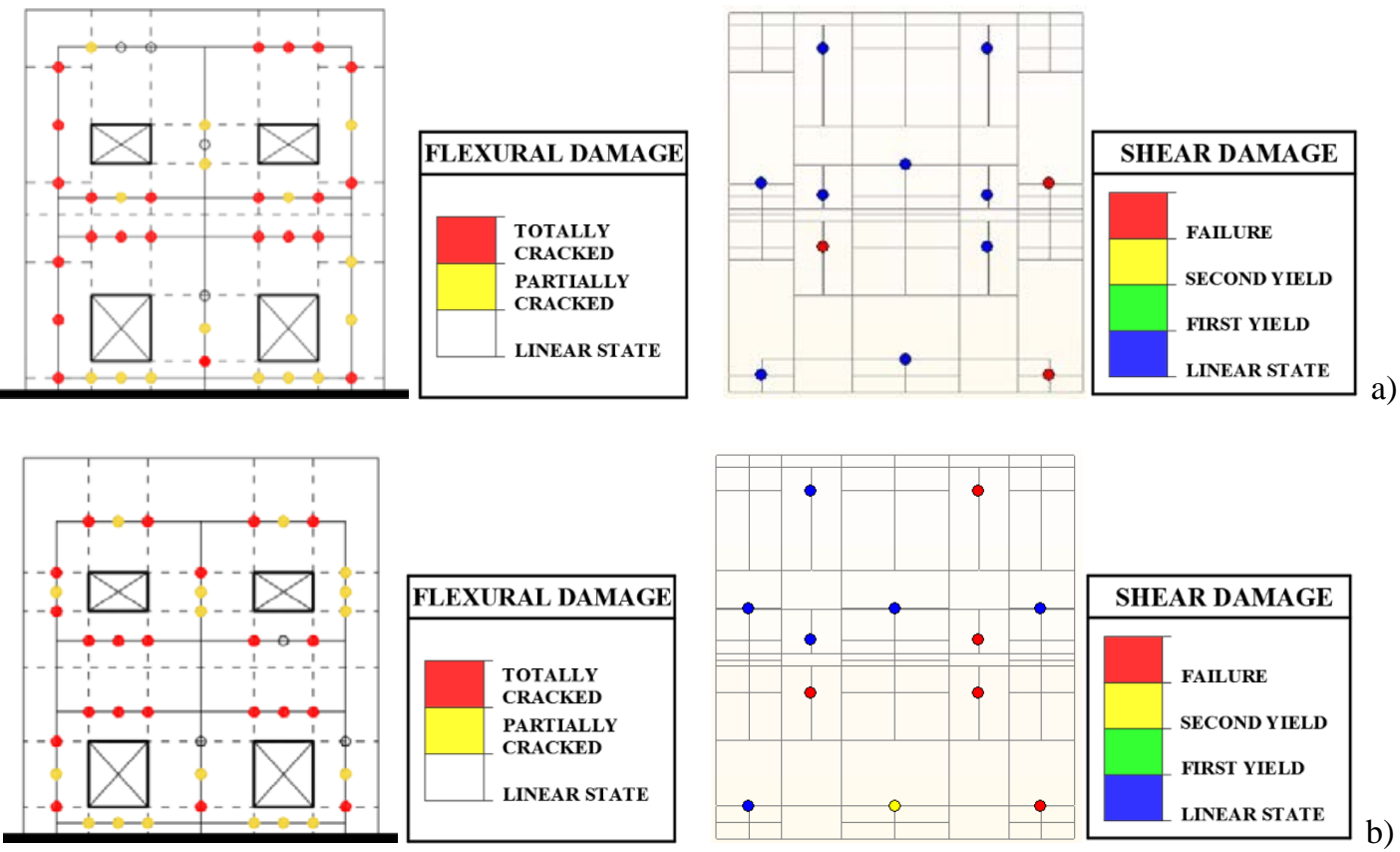

Figure 21. Damage patterns of scheme C according to the fiber EFM with Dolce's (a) and Augenti's model (b). 

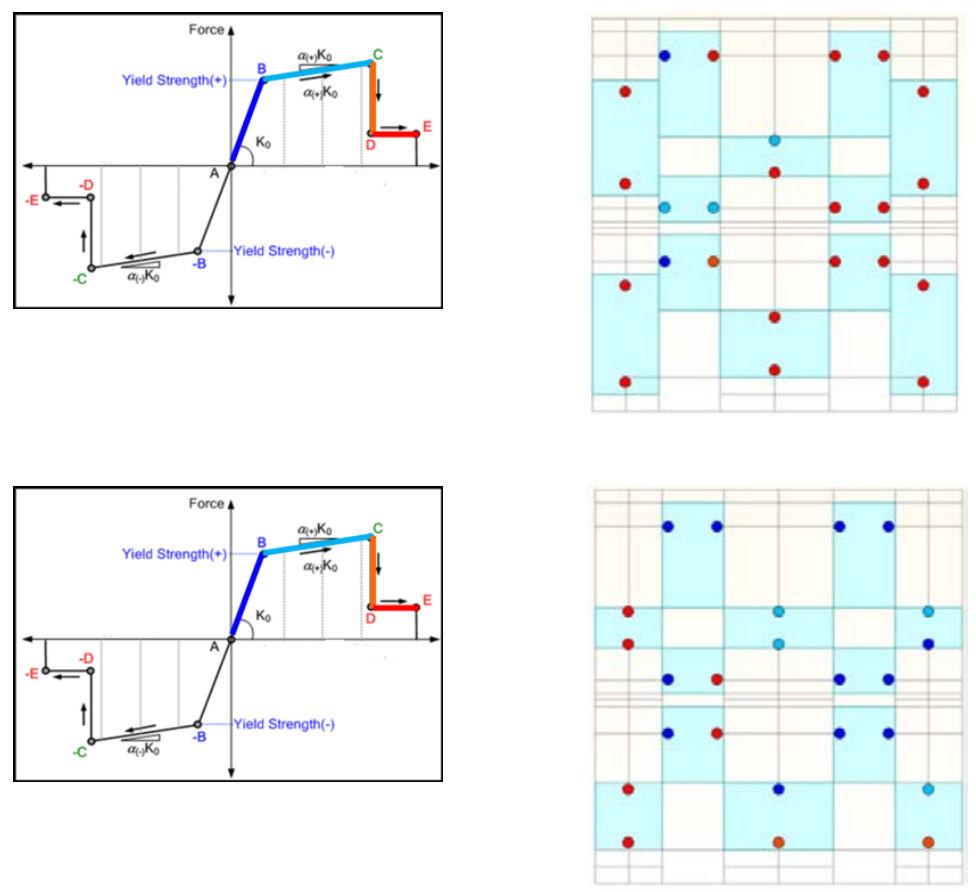

Flexural Damage
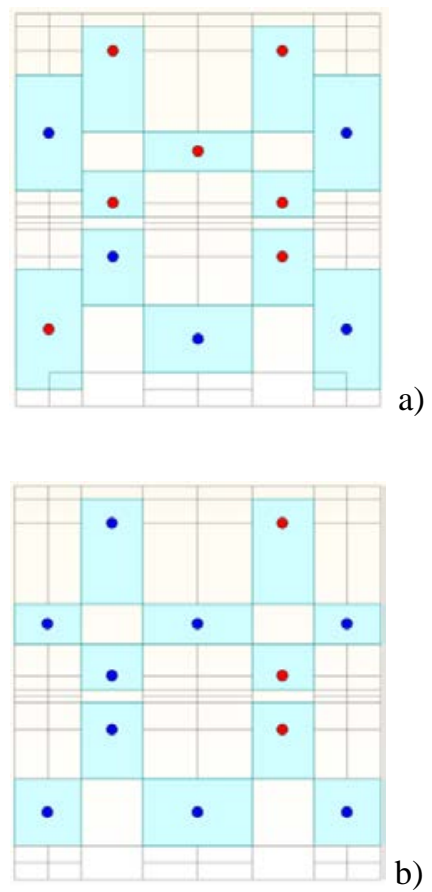

Shear Damage

Figure 22. Damage patterns of scheme C according to the EFM with concentrated hinges defined according to Dolce’s model (a) and Augenti’s model (b).

The prediction of damage evolution is also analysed by comparing the results provided by EF and FE models for the most representative loading steps (Figure 23). The attention is focused on the fiber EF models whose results match better the FEM predictions. Starting from the loading step corresponding to the yielding point for each model (Figure 23b), the initial concentration of shear cracks in the spandrels of the lower floor is well predicted by both EFM models. Once reached the peak point of the capacity curves, the prediction provided by the two EF models (Figure 23c) start to show different levels of accuracy with respect to the reference model. In particular, the EF model defined according to Augenti's criterion matches better the FEM prediction of shear damage with respect to the one defined according to Dolce's criterion. The concentration of shear damage in the spandrels is well predicted by Augenti's criterion, while Dolce's criterion slight underestimates this phenomenon. Both the models are not able to point out the shear cracking of the central pier at lower level of the wall, even if Augenti's model predicts the attainment of yielding state for this pier. Finally, in Dolce's model the beginning of the softening branch is attributed to the shear failure of the pier located at the right in the second level.

The results collected here strongly stress the influence of the pier's effective height on the accuracy of EFM results. The geometry assigned to the scheme under consideration results in a relevant variation of the piers effective height in the two criteria and consequently of their shear strength but also of the relative stiffness between the piers. These differences strongly affect the distribution of shear forces in the piers and the possibility for each one to attain its maximum shear capacity. The relevant differences observed in the damage predictions provided by the two EF models definitively confirm these phenomena. 


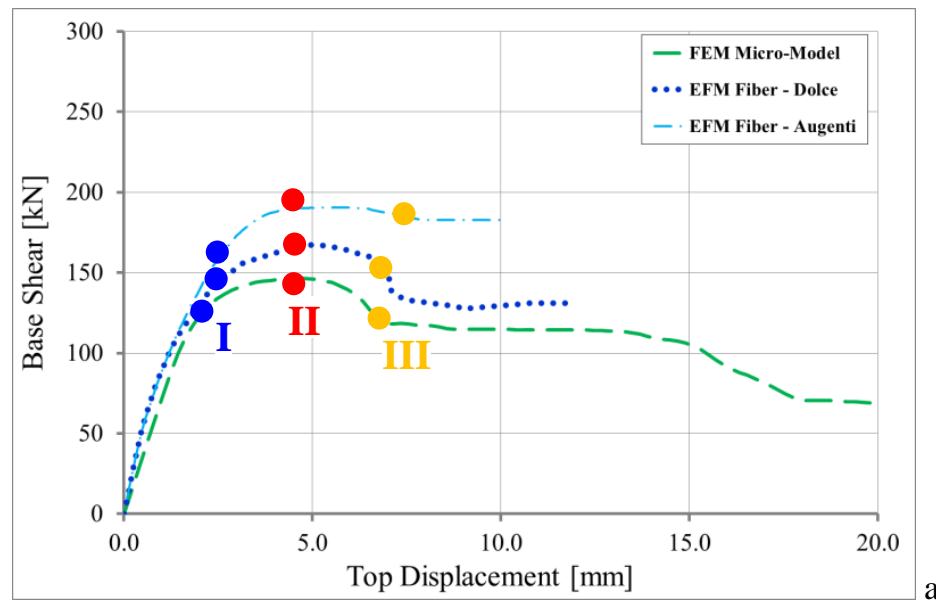

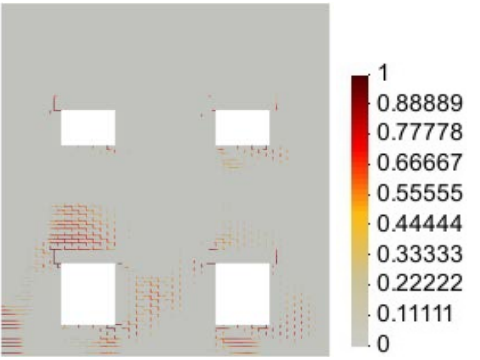

b-I)

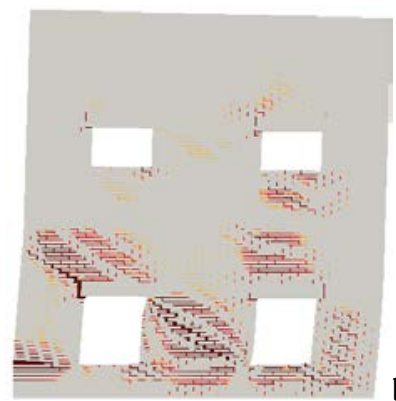

b-II)

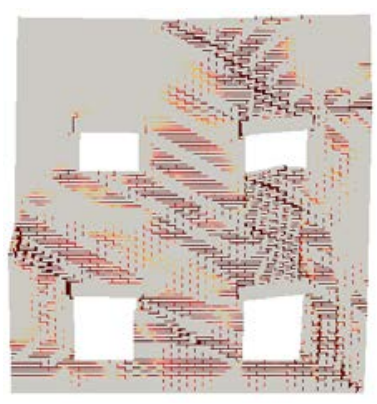

b-III)

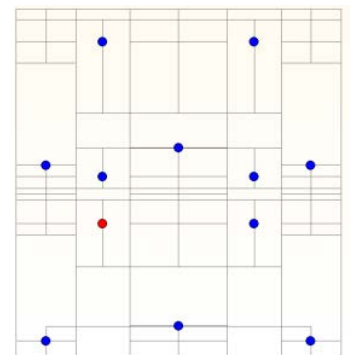

C-I)
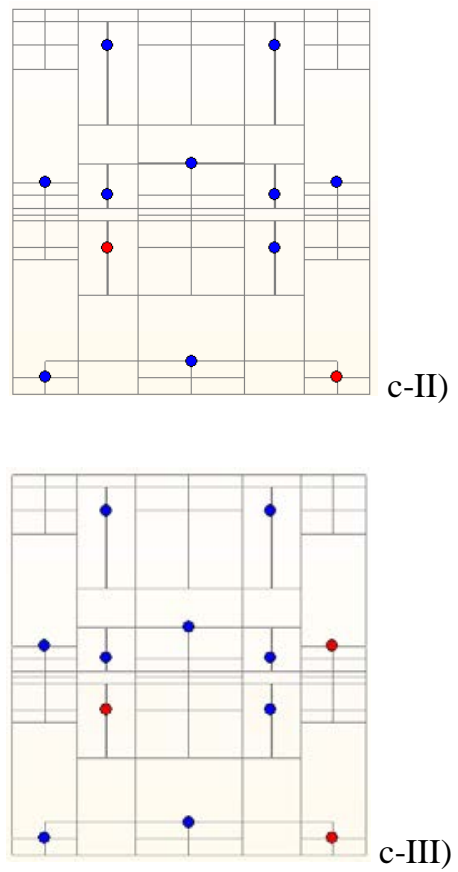
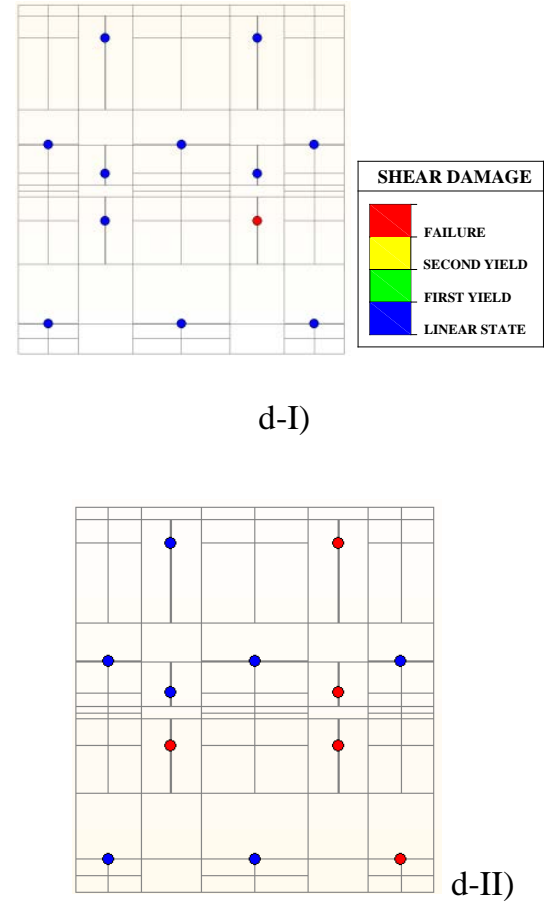

d-I)

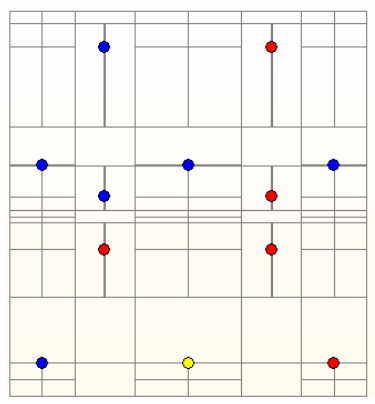

d-III)

Figure 23. Damage patterns corresponding to the steps identified in (a) for scheme $\mathrm{C}$ according to the FE micromodel (column b), fiber EFM with Dolce’s model (column c) and fiber EFM with Augenti's model (column d). 
The attention was then focused on the scheme D that produced the largest deviation between the FEM and EFM results in the previous linear elastic analyses [18] (Figure 10d). The aim of the present study of scheme D is to investigate the EFM accuracy in the non-linear field in case of extreme geometries. Figure 24 reports the results predicted by all the numerical models under consideration in terms of capacity curves and damage patterns. Also in this case, very high differences can be observed in the prediction of the maximum shear capacity of the wall between the EF models and the FEM one. In particular, the maximum shear capacity predicted by EFM overestimate in all the cases the FEM prediction $\left(V_{\max }=119.30 \mathrm{kN}\right)$. The overestimation of shear capacity with respect to the FEM prediction reaches a percentage of about $30 \%$ in the case of EFM with fiber approach $\left(V_{\max }=154.62 \mathrm{kN}\right.$ in the case of Dolce's model and $V_{\max }=157.49 \mathrm{kN}$ in the case of Augenti's model), while even more unconservative results are provided by the EF models with lumped springs, for which the prediction of the global shear capacity reaches a percentage difference of about $60 \%$ with respect to the FEM prediction ( $V_{\max }=185 \mathrm{kN}$ in the case of Dolce's model and $V_{\max }=193 \mathrm{kN}$ in the case of Augenti's model).

Although very far from FEM prediction, the two EF models with lumped hinges describe well the softening behaviour of masonry after the attainment of the peak shear capacity of the wall. As already observed for scheme C, a stepped post-peak path characterizes the capacity curves of the EF models of scheme D with lumped hinges. The activation of hinges is, however, strongly overestimated with respect to the FE model. In fact, the first appearance of the hinges is attained for a displacement two times higher than that corresponding to the beginning of the softening in the FEM curve. An anomalous post-peak behaviour is experienced by the two EF models with fiber discretization, as well as a plateaux after the attainment of the peak shear capacity.
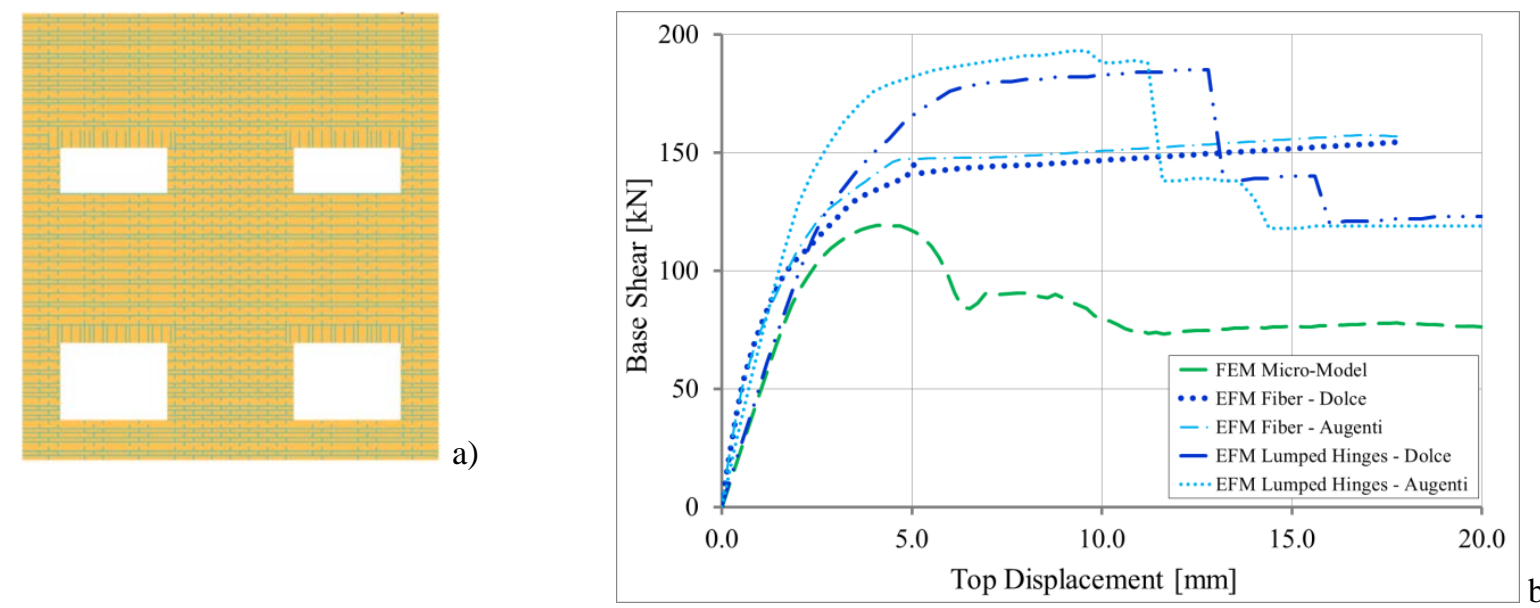

b)

Figure 24. Micro-model of scheme D (a) and comparison of EFM and FEM capacity curves.

Regarding the predictions of damage, Figure 25, Figure 26 and Figure 27 report the damage patterns provided by the FE micro-models and the EF models. Focusing on the fiber EF models, both the models match well the FEM predictions by showing severe damaging of all the spandrels and concentration of flexural cracks in the external piers, characterized by a higher slenderness with respect to the central ones. An analogue performance can be observed in the EF model with lumped springs defined according to Augenti's criterion, while a greater underestimation of the damage pattern can be observed in the corresponding Dolce's model. Finally, none of the EF models is able to describe the shear failure of the central pier at lower level, which represents the most evident failure mechanism predicted by the FE model. In the specific case of the EF model defined according to Dolce's criteria, the strong difference in the slenderness of the external piers with respect to the central one leads to an underestimation of shear damage and to an accentuation of the flexural mechanisms. 


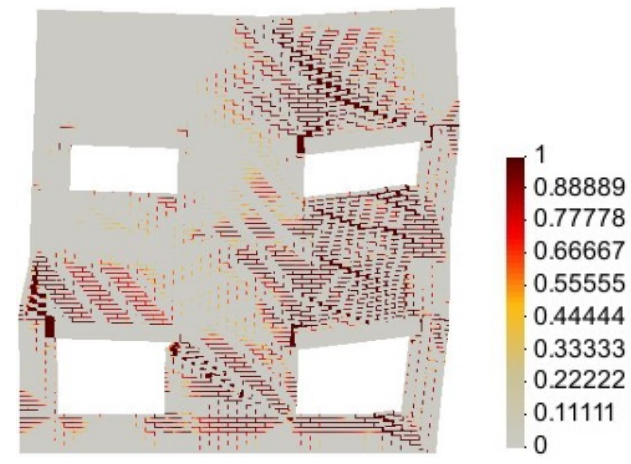

Figure 25. Damage patterns of scheme D according to the FE micro-model.
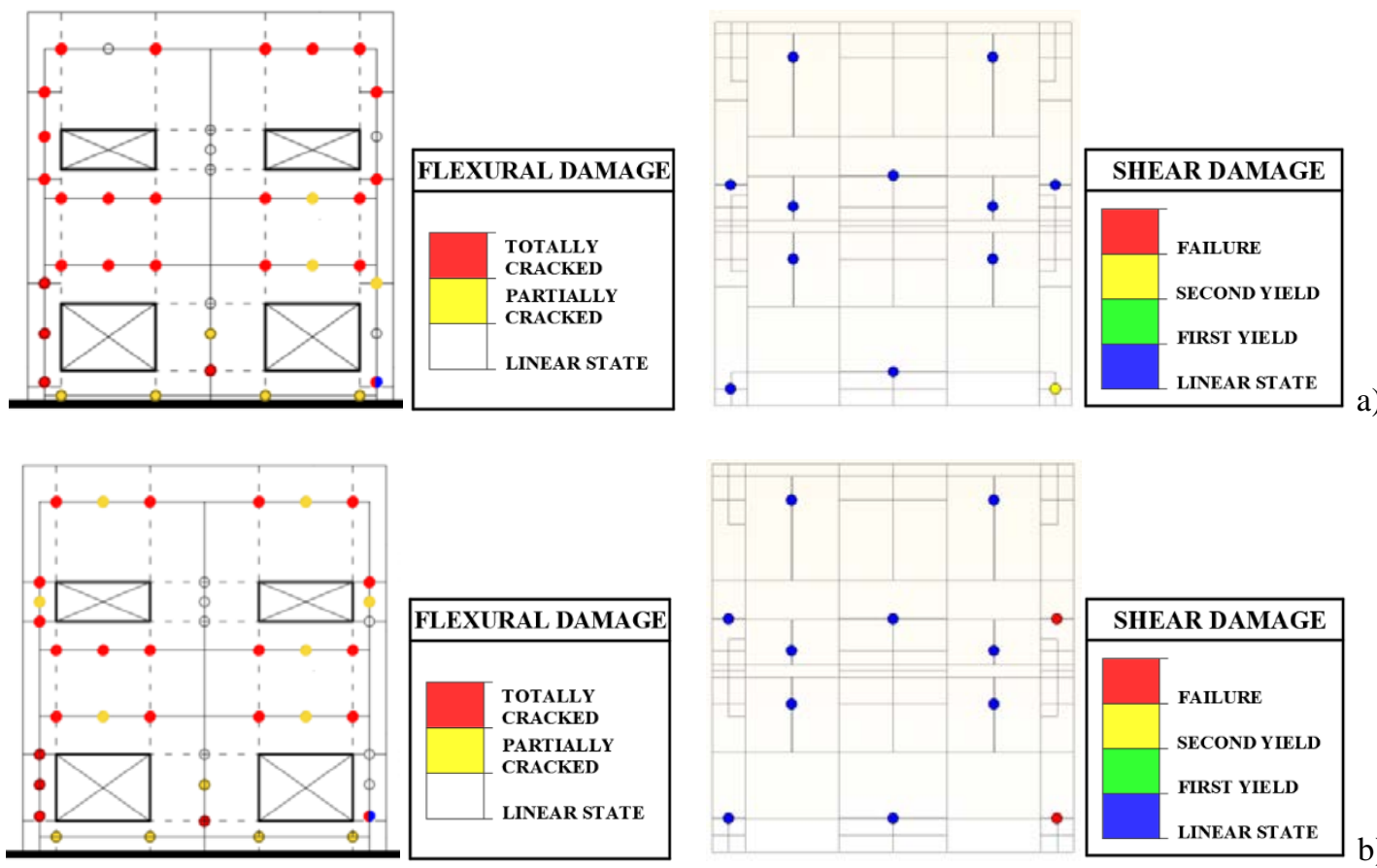

a)

Figure 26. Damage patterns of scheme D according to fiber EF with Dolce’s model (a) and Augenti’s model (b).

The results provided here by the non-linear analyses generally confirm the limits identified in the linear field [18]. Even if all the tested geometries are geometrically regular, in fact, the accuracy of the results provided by nonlinear EFM tends to decrease when the geometrical configuration of the walls becomes less comparable with the ideal frame configuration. Moving from frame-like to non-frame-like configurations, the consistency between the walls' geometry and the corresponding frame configuration decreases and, consequently, the accuracy of the results provided by EF non-linear models decreases, as already observed in the preliminary linear analyses. The distinction between frame-like and non-frame-like walls was introduced in [18] by providing numerical parameters able to express the correlation between the wall's geometry (geometrical proportions between piers and spandrels) and the accuracy of EFM in describing the wall's behaviour. This concept refers to the possibility to study a masonry panel as a mono-dimensional beam element. The ability of EFM to describe accurately the response of the façade wall decreases very significantly with the decreasing similarity between the masonry panel and a mono-dimensional beam. 

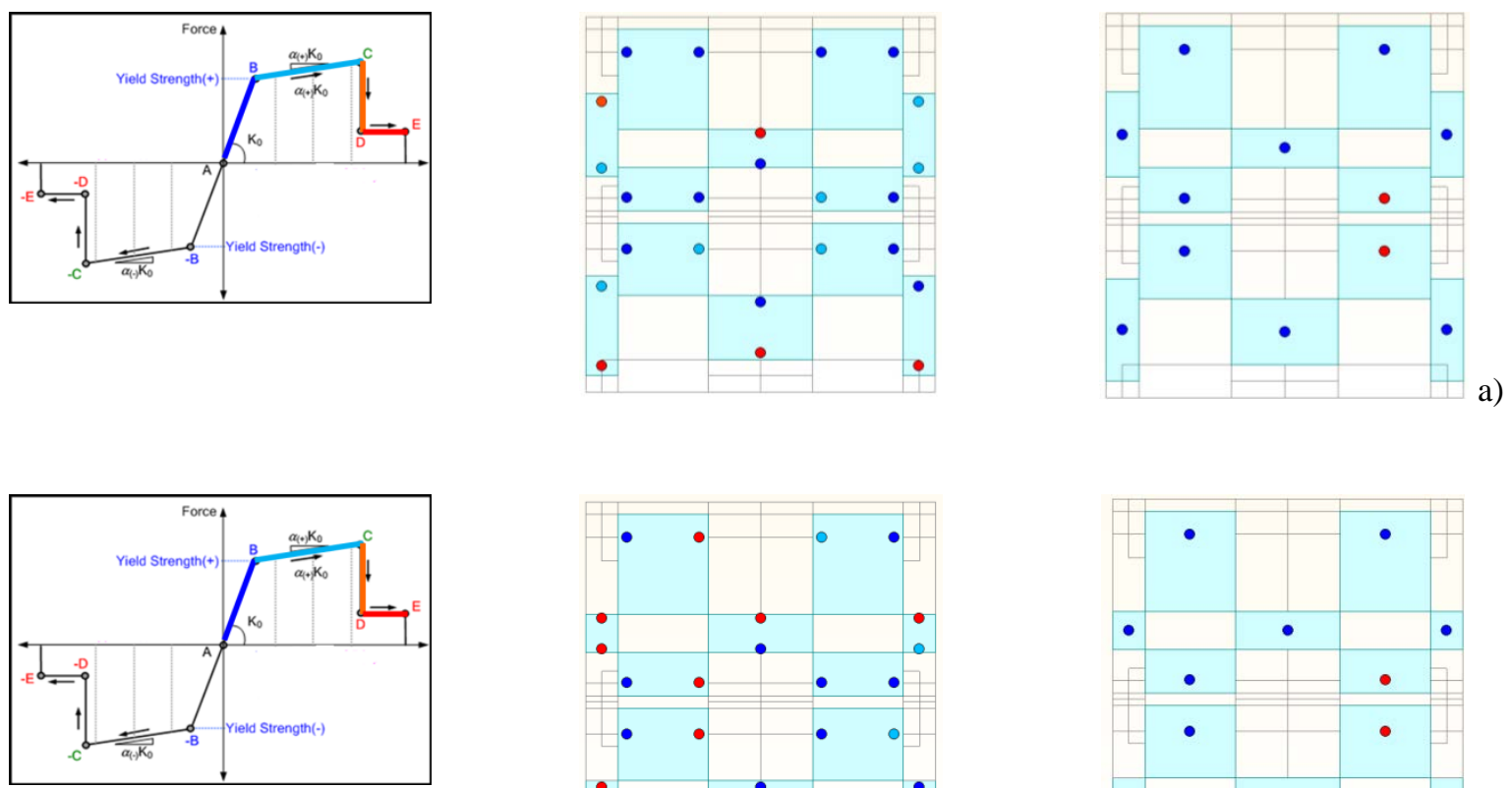

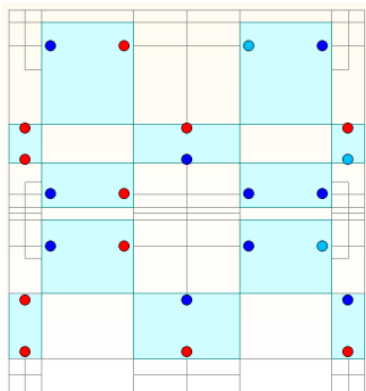

Flexural Damage

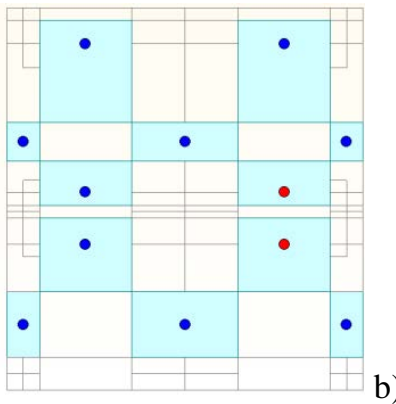

Shear Damage

Figure 27. Damage patterns of scheme C according to the EFM with concentrated hinges defined according to Dolce's model (a) and Augenti's model (b).

The comparison between the results obtained for the tested geometries (Figure 10) and those obtained for the reference wall (wall D of the prototype tested in Pavia - Figure 5) confirms the strong influence of the walls geometry on the modelling accuracy of the EFM. The regular geometries presented here can be considered representative of both frame-like and non-frame-like configurations. Focusing on the results provided by all the EF models, it is possible to observe negligible differences (percentage differences lower than 20\%) between EFM and FEM predictions for such schemes that already provided satisfactory results in the preliminary linear analyses [18]. This is the case of the reference wall (wall D of the prototype tested in Pavia - Figure 5) and the scheme A and B of Figure 10 that can be considered examples of regular frame-like configurations.

On the contrary, the two schemes reported in Figure 10c and Figure 10d fulfil the definition of non-frame-like configurations. For these geometries, differences greater than $30 \%$ can be observed in the results provided by the all EF models with respect to the corresponding FE model. In particular, a strong underestimation of the shear failures can be detected in the prediction of damage distribution provided by EF models. However, the non-linear results are characterized by a slight reduction of the differences between the EFM and the FEM with respect to the linear cases. In this respect, the higher accuracy shown by EFM in the non-linear field demonstrates a better performance of the approach in reproducing the redistribution of forces among the structural elements induced by the damage propagation.

\section{CONCLUSIONS}

The Equivalent Frame Method (EFM) is a very common approach currently applied by researchers and practitioners to the seismic assessment of existing URM buildings. However, the assumptions underlying this approach may not be fully compatible with the structural complexity of existing masonry constructions, especially in the case of historical buildings. With the aim to support a more careful and reliable use of the EFM approach, this paper presents a study about the modelling performance of this simplified method in the non-linear field. 
The results presented are part of a broader study [18, 23-24] aimed at investigating the capability of EFM to simulate the in-plane behaviour of regular and irregular URM walls. In particular, this paper presents a study of the modelling accuracy of EFM for regular URM walls in the non-linear field. The study is carried out by comparing the EFM with the FEM results. The EFM followed two different approaches. The first one considers a spread plasticity model to describe the flexural behaviour of masonry and lumped non-linear springs to simulate the shear behaviour. A second approach considers lumped plasticity, a very common numerical approach adopted by practitioners. The study assumes a reference FEM continuum micro-model in which both bricks and mortar joints are modelled with continuum 2D (plane-stress) finite elements [37]. Given the different theoretical principles and input parameters characterizing the two mechanical models (EFM and FEM), a preliminary calibration was performed on both models to ensure their ability to describe an experiment available in the scientific literature.

Starting from the results obtained in the linear field in a previous work by the authors [18], the present study leads to the identification of specific ranges of applicability of EFM to URM walls characterized by regular geometry. The sample cases represent a selection of a wider set of regular two-storey walls whose analyses in the linear field provide geometrical criteria on the applicability of EFM. The comparative study of EF and FE non-linear models confirms that the EFM limitations in the linear field can also be found in the non-linear one. As for the linear elastic analysis, there is a strong correlation between the wall geometry and the accuracy of the EFM results. In particular, an inverse proportionality between the ratio of piers and spandrels cross-sections dimensions and the accuracy of EFM results can be observed. More specifically, the results show that the EFM becomes insufficiently accurate in describing the seismic behaviour of regular masonry walls when they include very squat panels and, in particular, when the spandrels' height becomes very large with respect to the entire height of the wall, i.e. greater than $60 \%$. The non-linear results demonstrate than even in the case of regular geometries, the accuracy of EFM tends to decrease as the geometrical affinity with an ideal frame configuration decreases.

The results provided by the non-linear analyses generally show the strong dependency of EFM performance on the wall geometry. A crucial role is played by the identification of the geometrical configuration of the structural components in the EFM. The modelling performance of the two criteria proposed by Dolce [1] and Augenti [2] is investigated as for the definition of the effective height of the piers. All the case studies are modelled by assuming the frame discretization deriving from the application of the two mentioned criteria. A greater accuracy characterizes Dolce's model in the prediction of the strength capacity of the studied schemes, while Augenti's model shows better performance in the prediction of the damage patterns. The study shows the importance to calibrate carefully the geometrical configuration of the piers to reach a correct simulation of the structural performance of URM walls.

The results provided by the non-linear analyses show remarkable differences among the different models in the simulation of flexural and shear failure mechanisms. The analysis of the results provided by EFM for the four selected walls schemes shows the limitations that these approaches may experience in the simulation of shear damage and failure mechanisms. A more accurate description of shear damage and strength in piers and spandrels by means of EFM may require a further detailed calibration of the mechanical models for the shear response based on experimental and numerical evidence.

\section{ACKNOWLEDGEMENTS}

The present research has received financial support from the University “G. D’Annunzio” of Chieti-Pescara (ex$60 \%$ funds) and from the ReLUIS program 2014-2016. The authors gratefully acknowledge the support of both institutions.

CSP Fea is acknowledged for providing the software MIDAS Gen (C [44] used for the implementation of the EFM models in this work. CIMNE (International Center for Numerical Methods in Engineering) is also acknowledged for providing the softwares GID (C) [61] and Kratos Multiphysics [59-60] used for the implementation of the FE micro-models.

\section{REFERENCES}

1. Dolce M. 1991, Schematizzazione e modellazione degli edifici in muratura soggetti ad azioni sismiche. L'industria delle Costruzioni, 25: 44-57 [in Italian].

2. Augenti N. 2004, Il calcolo sismico degli edifici in muratura. UTET Libreria. Torino, Italy [in Italian].

3. Roca P, Cervera M, Gariup G, Pelà L. 2010, Structural analysis of masonry historical constructions. Classical and advanced approaches. Archives of Computational Methods in Engineering, 17, 299-325. 
4. Cundall PA. 1988, Formulation of a three-dimensional distinct element model - Part I: A scheme to detect and represent contacts in a system composed of many polyhedral blocks. International Journal of Rock Mechanics and Mining Sciences \& Geomechanics Abstracts, 25(3):107-116.

5. Hart RD, Cundall PA, Lemos J. 1988, Formulation of a three-dimensional distinct element model - Part II: Mechanical calculations for motion and interaction of a system composed of many polyhedral blocks. International Journal of Rock Mechanics and Mining Sciences \& Geomechanics Abstracts, 25(3):117-125.

6. Page AW. 1978, Finite element model for masonry. Journal of Structural Div. ASCE, 104(8): 1267-1285.

7. Pegon P, Anthoine A. 1997, Numerical strategies for solving continuum damage problems with softening: application to the homogenization of masonry. Computers and Structures, 64(1-4): 623-642.

8. Lourenco PB, Rots JG, Blaauwendraad J. 1998, Continuum model for masonry: Parameter estimation and validation. Journal of Structural Engineering 1998, 124(6): 642-652.

9. Roca P, Molins C, Mari AR. 2005, Strength capacity of masonry wall structures by the equivalent frame method. Journal Structural Engineering - ASCE; 131(10):1601-1610. DOI: 10.1061/(ASCE) 0733-9445.

10. Caliò I, Marletta M, Pantò B. 2012, A new discrete element model for the evaluation of the seismic behaviour of unreinforced masonry buildings. Engineering Structures, 40:327-338.

11. Applied Technology Council (ATC). 2000, Pre-standard and commentary for the seismic rehabilitation of buildings, FEMA 356, Washington DC.

12. Marques R, Lourenço PB. 2011, Possibilities and comparison of structural component models for the seismic assessment of modern unreinforced masonry buildings. Computers and Structures, 89: 2079-2091.

13. Marques R, Lourenço PB. 2014, Unreinforced and confined masonry buildings in seismic regions: validation of macro-element models and cost analysis. Engineering Structures, 64: 52-67.

14. Calderini C, Cattari S, Lagomarsino S. 2009, In plane seismic response of unreinforced masonry walls: comparison between detailed and equivalent frame models. COMPDYN 2009 - ECCOMAS Thematic Conference on Computational Methods in Structural Dynamics and Earthquake Engineering, Rhodes, Greece.

15. Raka E, Spacone E, Sepe V, Camata G. 2015, Advanced frame element for seismic analysis of masonry structures: model formulation and validation. Earthquake Engineering \& Structural Dynamics, 44: 2489-2506. DOI: 10.1002 /eqe.2594.

16. Magenes G, Penna A, Senaldi I, Rota M, Galasco A. 2014, Shaking table test of a strengthened full scale stone masonry building with flexible diaphragms. International Journal of Architectural Heritage, 8(3): 349-375.

17. Penna A, Senaldi I, Galasco A, Magenes G. 2015, Numerical Simulation Of Shaking Table Tests On Full-Scale Stone Masonry Buildings. International Journal of Architectural Heritage, DOI: 10.1080/15583058.2015.1113338.

18. Siano R, Sepe V, Camata G, Spacone E, Roca P, Pelà L. 2017, Analysis of the performance in the linear field of Equivalent-Frame Models for regular and irregular masonry walls. Engineering Structures, 145, 190-210, doi 10.1016/j.engstruct.2017.05.017.

19. Parisi F, Augenti N. 2013, Seismic capacity of irregular unreinforced masonry walls with opening. Earthquake Engineering \& Structural Dynamics, 42: 101-121.

20. Huerta S. 2008, The analysis of masonry architecture: a historical approach. Archit. Sci. Rev, 51 (2008) 297328. http://dx.doi.org/10.3763/asre.2008.5136.

21. Lourenco PB. 2002, Computations on historic masonry structures. Progress in Structural Engineering and Materials, 4 (2002) 301-319. http://dx.doi.org/10.1002/pse.120.

22. Quagliarini E, Maracchini G, Clementi F. 2017, Uses and limits of the Equivalent Frame Model on existing unreinforced masonry buildings for assessing their seismic risk: A review. Journal of Building Engineering, 10: 166-182. DOI: http://dx.doi.org/10.1016/j.jobe.2017.03.004.

23. Siano R, Camata G, Sepe V, Spacone E, Roca P, Pelà L. 2016, Numerical validation of Equivalent-Frame models for URM walls. VII European Congress on Computational Methods in Applied Sciences and Engineering - ECCOMAS, Crete Island, Greece.

24. Siano R, Camata G, Sepe V, Spacone E, Roca P, Pelà L. 2017, Finite Elements vs. Equivalent-Frame Models for URM walls' in-plane behaviour. $16^{\text {th }}$ World Conference on Earthquake 16WCEE, Santiago del Chile, January 2017.

25. Calvi GM, Magenes G. 1994, Experimental research on response of URM building systems. Proceedings of the U.S. - Italian Workshop on Guidelines for Seismic Evaluation and Rehabilitation of Unreinforced Masonry Buildings. 
26. Penna A, Rota M, Mouyiannou A, Magenes G. 2013, Issues on the use of time-history analysis for the design and assessment of masonry structures, in: COMPDYN 2013: $4^{\text {th }}$ ECCOMAS Thematic Conference on Computational Methods in Structural Dynamics and Earthquake Engineering, 2013, Kos Island, Greece.

27. Nakamura Y, Derakhshan H, Griffith MC, Magenes G, Sheikh AH. 2017, Applicability of nonlinear static procedures for low-rise unreinforced masonry buildings with flexible diaphragms. Engineering Structures, 137 1-18. DOI: http://dx.doi.org/10.1016/j.engstruct.2017.01.049.

28. Haller P. 1960, The physics of fired brick: Part One strength properties. Library and Community of Building Resistant Structures, 929.

29. Croci G. 1995, The Colosseum: safety evaluation and preliminary criteria of intervention. SAHC 1995, $1^{\text {st }}$ International Seminar on Structural Analysis of Historical Constructions, Barcelona, Spain.

30. Gonzalez A, Casals A, Roca P, Gonzalez JL. 1993, Studies of Gaudi’s Cripta de la Colonia Guell. IABSE Symposium. Structural Preservation of the Architectural Heritage, 457-464. Rome, Italy.

31. Lourenco PB. 1996, Computational strategies for masonry structures. Ph.D. Thesis. TU Delft.

32. Pelà L, Cervera M, Roca P. 2013, An orthotropic damage model for the analysis of masonry structures. Construction and Building Materials, 41:957-967.

33. Pelà L, Cervera M, Roca P. 2011, Continuum damage model for orthotropic materials: Application to masonry. Computer Methods in Applied Mechanics and Engineering, 200:917-930.

34. Lourenco PB, Rots JG. 1997, A multi-surface interface model for the analysis of masonry structures. Journal of Engineering Mechanics - ASCE; 123(7): 660-668.

35. Gambarotta L, Lagomarsino S. 1997, Damage models for the seismic response of brick masonry shear walls. Part I: The mortar joint model and its applications. Earthquake Engineering and Structural Dynamics, 26: 423439.

36. Massart TJ, Peerlings RHJ, Geers MGD. 2007, An enhanced multi-scale approach for masonry wall computations with localization of damage. International Journal for Numerical Methods in Engineering, 69(5):1022-1059.

37. Petracca M, Pelà L, Rossi R, Oller S, Camata G, Spacone E. 2016, Regularization of first order computational homogenization for multiscale analysis of masonry structures. Computational Mechanics, 57:257-276. DOI: 10.1007/s00466-015-1230-6.

38. Petracca M, Pelà L, Rossi R, Zaghi S, Camata G, Spacone E. 2017, Micro-scale continuous and discrete numerical models for nonlinear analysis of masonry shear walls. Construction and Building Materials, 149:296-314.

39. Magenes G, Della Fontana A. 1998, Simplified Non-linear Seismic Analysis of Masonry Buildings. Proc. of the British Masonry Society, 8: 190-195.

40. Lagomarsino S, Penna A, Galasco A, Cattari S. 2013, TREMURI program: an equivalent frame model for the nonlinear seismic analysis of masonry buildings. Engineering Structures, 56:1787-1799.

41. Penna A, Lagomarsino S, Galasco A. 2014, A nonlinear macroelement model for the seismic analysis of masonry buildings. Earthquake Engineering and Structural Dynamics, 43: 159-179. DOI: http://dx.doi.org/10.1002/eqe.2335.

42. Spacone E, Filippou FC, Taucer FF. 1996, Fibre beam-column model for nonlinear analysis of RC frames: part I. Formulation. Earthquake Engineering and Structural Dynamics, 25(7):711-725.

43. Spacone E, Filippou FC, Taucer FF. 1996, Fibre beam-column model for nonlinear analysis of R/C frames: part II. Applications. Earthquake Engineering and Structural Dynamics, 25(7):727-742.

44. MIDAS Gen@, MIDAS Information Technology Co., http://www.cspfea.net/

45. Kent DC, Park R. 1971, Flexural members with confined concrete. Journal of the Structural Division, ASCE; 97(7): 1969-1990.

46. Scott BD, Park R, Priestley MJN. 1982, Stress-strain behavior of concrete confined by overlapping hoops at low and high strain rates. ACI Journal Proceedings, 79(1): 13-27.

47. De Santis S, De Felice G. 2014, A fibre beam-based approach for the evaluation of the seismic capacity of masonry arches. Earthquake Engineering and Structural Dynamics, 43(11): 1661-1681 DOI: 10.1002/eqe.2416.

48. EN 1996-1-1. 2004, Eurocode 6. Design of masonry structures - part 1-1: Common rules for reinforced and unreinforced masonry structures, CEN, Brussels, Belgium.

49. Italian Building Code. D.M. 14/01/2008: Norme Tecniche per le Costruzioni. Italian Ministry of Infrastructures and Transportation. G.U. S.O. n. 30 of 04/02/2008 [in Italian]. 
50. MIT, Ministry of Infrastructures and Transportation, Circ. C.S.Ll.Pp. No. 617 of 2/2/2009. Istruzioni per l'applicazione delle nuove norme tecniche per le costruzioni di cui al D.M. del 14 Gennaio 2008. G.U. S.O. n.27 of 26/2/2009, No. 47 [in Italian].

51. Applied Technology Council (ATC). 1999, Evaluation of earthquake damaged concrete and masonry wall buildings, FEMA 306, Federal Emergency Management Agency: Washington DC, USA.

52. Turnšek V, Čačovič F. 1970, Some experimental results on the strength of brick masonry walls. Proceedings of the 2nd International Brick \& Block Masonry Conference, Stoke-on-Trent, United Kingdom; 149-156.

53. Tomaževič M. 1990, Masonry structures in seismic areas - a state of art report. $9^{\text {th }}$ European Conference on Earthquake Engineering, Moscow, vol. A, 247-302.

54. Calvi GM, Magenes G, Magenes G, Pavese A. 1992, Experimental and numerical investigation on a brick masonry building prototype. Report 1.1 - Design of the Experimental Tests, G.N.D.T., Pavia, Italy.

55. Magenes G, Calvi GM, Kingsley R. 1995, Seismic testing of a full-scale, two-story masonry building: Test procedure and measured experimental response. Experimental and numerical investigation on a brick masonry building prototype - Report 3.0, G.N.D.T., Pavia, Italy.

56. Binda A, Mirabella Roberti G, Tiraboschi C, Abbaneo S. 1994, Measuring masonry material properties. Proceedings of the U.S. - Italian Workshop on Guidelines for Seismic Evaluation and Rehabilitation of Unreinforced Masonry Buildings.

57. Berto L, Saetta A, Scotta R, Vitaliani R. 2002, An orthotropic damage model for masonry structures. International Journal for Numerical Methods in Engineering, 55: 127-157.

58. Gambarotta L, Lagomarsino S. 1997, Damage models for the seismic response of brick masonry shear walls. Part II: The continuum model and its applications. Earthquake Engineering and Structural Dynamics, 26: 441462.

59. Dadvand P, Rossi R, Oñate E. 2010, An object-oriented environment for developing finite element codes for multi-disciplinary applications. Archives of Computational Methods in Engineering, 17 (3): 252-297.

60. Dadvand P, Rossi R, Gil M, Martorell X., Cotela J., Juanpere E., Idelsohn SR, Oñate E. 2013, Migration of a generic multi-physics framework to HPC environments, Computers and Fluids, 80: 301-309.

61. GID: The personal pre and post-processor, 2002.

62. Brandonisio G, Lucibello G, Mele E, De Luca A. 2013, Damage and performance evaluation of masonry churches in the 2009 L'Aquila earthquake, Engineering Failure Analysis 34: 693-714. DOI: http://dx.doi.org/10.1016/j.engfailanal.2013.01.021.

63. Cattari S, Giongo L, Marino S, Lin Y, Schiro G, Ingham JM, Dizhur D. 2015, Numerical simulation of the seismic response of an earthquake damaged URM building. In: New Zealand Society for Earthquake Engineering Technical Conference 2015 Conference. 